\title{
Article \\ Study on the Combined Effect of Multiple Passive Energy-Saving Methods for Rural Houses with Cold Alleys
}

\author{
Xingbo Yao ${ }^{1, *(\mathbb{D})}$, Shuo Han ${ }^{2}$ and Bart Julien Dewancker ${ }^{1}$ (D) \\ 1 Faculty of Environmental Engineering, The University of Kitakyushu, Kitakyushu 808-0135, Japan; \\ bart@kitakyu-u.ac.jp \\ 2 School of Communication Engineering, Xidian University, Xi'an 710071, China; hanshuo1991sure@163.com \\ * Correspondence: yaohanhome@gmail.com; Tel.: +81-90-2968-8668
}

Citation: Yao, X.; Han, S.;

Dewancker, B.J. Study on the Combined Effect of Multiple Passive Energy-Saving Methods for Rural Houses with Cold Alleys. Appl. Sci. 2021, 11, 5636. https://doi.org/ 10.3390/app11125636

Academic Editors: Jennifer Keenahan, Hassan Hemida and Sébastien Poncet

Received: 5 May 2021

Accepted: 17 June 2021

Published: 18 June 2021

Publisher's Note: MDPI stays neutral with regard to jurisdictional claims in published maps and institutional affiliations.

Copyright: (c) 2021 by the authors. Licensee MDPI, Basel, Switzerland. This article is an open access article distributed under the terms and conditions of the Creative Commons Attribution (CC BY) license (https:// creativecommons.org/licenses/by/ $4.0 /)$.
Abstract: China's rural houses are mostly courtyard-style independent houses. Such houses have certain characteristics, e.g., small mutual influences between houses, strong transformation flexibility, and an easier approach to using the natural environment to develop passive energy-saving characteristics. Therefore, rural houses have large energy-saving potential. In this study, for the first time, the cold alleys between buildings were used as an energy source for passive cooling and ventilation. Traditional houses in Shuhe, China, were used as a case study. The cold alleys in the settlements were used to compensate for the natural conditions in summer, and the cold air in the cold alley was introduced into each room using hot-press ventilation and by employing an accumulation effect from a corresponding patio. The room was ventilated and cooled, and air ducts were used to connect the rooms on both sides of the patio to improve the cooling efficiency. The research variables included the existence or non-existence of wall heat radiation (WHR), and the importance and influence of the WHR on the indoor conditions were verified. The cold air trapped in the new system formed an air partition wall, effectively blocking the direct influence of solar radiation on the room, reducing the heat transfer rate of the residential wall, and consuming part of the heat. In winter, based on using air ducts as supporting members, a glass roof was added to the patio, which improved the heat storage capacity of the patio and turned it into a constant-temperature heater for heating the building interior. Based on calculations, in the new system without WHR, the annual cooling load reduction was 55,417.33 kWh. With WHR, the annual cooling load reduction was $28,537.57 \mathrm{kWh}$. The annual cooling load of the air insulation wall of the new system was reduced to $1133.7 \mathrm{kWh}$. In winter, using the glass roof to increase the heat storage capacity of the patio reduced the heating load to $54,537.78 \mathrm{kWh}$.

Keywords: CFD; passive cooling; passive heating; air insulation wall; cold alley; rural house

\section{Introduction}

\subsection{Motivation}

In 2016, the total population of the world reached 7.44 billion, and it is still rising [1] Architecture is undoubtedly a necessary condition for human existence, not only for residences, but for industry, agriculture, commerce, and other activities (e.g., buildings are needed as carriers for production or as offices). In view of the rapid growth of the population, the construction industry must also develop at the same speed to address such growth. Currently, the energy consumed by the construction industry comprises the largest part of the world's energy consumption [2]. The energy consumption in commercial, residential, and public buildings accounts for 30-40\% of the world's total energy consumption [3]. In developing countries, this situation is even more pronounced. According to data from the Building Energy Research Center of Tsinghua University, China in 2018, the total energy consumption used in the building industry in 2018 reached $1123 \mathrm{Mtce}$; this was divided into commercial and non-commercial consumption energy. In China, the amount of energy consumed by residences was 1032 Mtce (the equivalent of one million tons of coal, 
1 Mtce $=20-30 \mathrm{GJ})$, accounting for $20 \%$ of the country's total energy consumption. The total annual carbon dioxide emissions of the residences were approximately 2.2 billion tons. The energy consumption of residences in 2018 was almost double that of 2001, and the per capita energy consumption increased from $291 \mathrm{kgce} / \mathrm{cap}$ to $739 \mathrm{kgce} / \mathrm{cap}$ ("Kgce" is the energy of $1 \mathrm{~kg}$ of standard coal and "cap" is the energy consumption per capita) [4]. This phenomenon has aroused the attention of scholars, who have begun to try to use renewable energy such as solar energy, wind energy, biofuel, biomass energy, geothermal energy, and hydroelectric power generation to put forward various theories and approaches for residential energy conservation [5]. This is a good beginning. Although scholars and architects continue to work on improving residential energy efficiency, the results are often not as expected. Liu [6] mentioned that it is unreasonable to implement a unified technology and energy consumption indicator system for low-energy buildings. The joint application of key technologies is an important strategy to achieve low energy consumption goals. It is predicted that by 2050, there will be twice as much energy consumption and building-related carbon emissions today than the current levels, or even more [7].

Most scholars and architects only focus on energy conservation issues in cities. They refer to successful cases of energy-saving in developed countries, and formulate a large number of similar building codes and laws to restrict the energy consumption of urban buildings. This approach has achieved certain results [8]. However, the effectiveness of saving energy depends on the national conditions. In China, $42.65 \%$ of people live in rural areas [9]. This energy consumption is also considerable, and thus, there is great energy-saving potential. China's urban residential buildings are mostly high-rise, centralized residential buildings. Once they are completed, it is difficult to carry out large-scale reconstruction. Therefore, the energy consumption issues are mainly considered before construction. In contrast, most rural residential buildings adopt an independent courtyardstyle residence mode, and the connections between buildings are not close. Any small-scale renovation of any building will not have a significant impact on other surrounding buildings [10]. In addition, rural buildings are generally closer to nature, and can effectively use the surrounding natural environment for passive energy-saving designs. If the unique advantages of rural courtyard-style residential buildings can be efficiently used and concepts of passive design can be introduced into the designs of rural buildings, these will greatly reduce energy consumption, and effectively improve energy utilization. Therefore, this study took a courtyard-style residential building as a case study and facilitated a passive transformation of the building. Its purpose was to save energy by reducing the building's cooling load in summer and its heating load in winter.

\subsection{Previous Studies}

Rural areas are an important part of a country, and the energy consumption of their buildings must be considered. Rural building energy consumption has received extensive attention worldwide, especially in developing countries, where consumption is even more important. Various countries have been exploring reasonable and convenient methods for reducing the energy consumption of rural buildings. The methods include economic means, the introduction of relevant policies, comprehensive data analyses, and the explorations of energy-saving technologies. Satish et al. [11] established a comprehensive database for analyzing the historical characteristics of the energy transfer and consumption patterns of rural and urban households in India. They constructed a per capita energy balance sheet for the urban and rural households in each state for 2004, 2009, and 2011. By comparing the energy consumption values of rural and urban households in low-, medium-, and high-income state and analyzing emission levels, they determined the characteristics of the relationship between energy transfer and income. Martinson et al. [12] used an instrumental variable method to study the impacts of credit on the energy consumption for clean cooking in rural households. The results showed that the impact of the amount of credit received for clean cooking energy expenditures was more pronounced for rural households in the eastern region than for rural households in other regions. The study also explored the importance 
of credit for energy consumption and provided policy recommendations for increasing the energy consumption for clean cooking. Lu et al. [13] showed that the proportion of non-commercial energy in the agricultural and pastoral areas in Qinghai Province was $52.89 \%$ and was affected by the "returning farmland to forest" policy and the "returning farmland to grassland project." In addition, they indicated that the structure of household energy consumption has changed from that based on traditional biomass to that based on a combination of coal and other energy sources. Generally, households with different cultural backgrounds have different energy consumption patterns. Compared with low-income households, high-income households consume more energy, and the energy flows more frequently. Shimei et al. [14] provided a systematic overview of the energy consumption of rural households in China from 1985 to 2013, based on seven energy sources and five end-use requirements. In addition, the energy consumption of rural households was compared based on the volumes, fuel mixes, and demand structures. It was ultimately discovered that biomass continues to account for the main part of the energy supply of rural households in China and that cooking and space heating are the most energy-consuming needs. The overall energy efficiency of rural households was determined as $33 \%$. Marina et al. [15] adopted a "people and pixels" method, based on combining household head interviews with remote sensing analyses of land use and land cover changes. The results of the study showed that although kerosene is the main energy source for cooking and lighting in cities, firewood and flashlights are used more frequently in rural areas, although there are relatively few households selling firewood and charcoal. Yu et al. [16] studied the dynamic relationships between the rural GDP, rural energy consumption, and rural investment, based on a provincial panel data set from 1995-2010. The results showed that it is feasible to promote economic development by accelerating the optimization and upgrading of the rural industrial structure, e.g., by encouraging and promoting the use of green energy. Shuwen et al. [17] estimated the consumptions of biogas, manure, and solar energy in rural households, and established a time series for the actual energy consumption in rural households. The effective energy consumption was measured based on the thermal efficiency of the fuel as found in the existing literature and revealed the main characteristics and trends of energy structure changes. The results showed that in 2015, the per capita actual energy consumption and effective energy consumption reached $546.4 \mathrm{kgce}$ and $142.5 \mathrm{kgce}$, respectively. Huanguang et al. [18] studied the impacts of rising wage rates on China's rural energy consumption structures. They produced a unique panel data set based on two rounds of surveys conducted for 409 rural households in four provinces. The results showed that the village wage level had a significant negative impact on the traditional biomass energy consumption and a significant positive impact on the electricity and energy consumption. Beatriz et al. [19] proposed a method for using low-cost information and communication technologies to improve the energy efficiency and comfort conditions of public buildings. The results showed inefficient consumption patterns and discomfort, and users were encouraged to take action and to adjust municipal policies. Mohammad et al. [10] studied the adoption of multi-standard decision support tools for transformation projects in four representative climatic environments in Iran. Based on the economic feasibility, environmental impact, and comfort benefits, they defined the best retrofitting strategy for rural buildings. According to the results, in different climate zones, the primary energy demand was reduced by $46 \%$ to $55 \%$, carbon emissions were reduced by $40 \%$ to $51 \%$, and thermal comfort was improved by $23 \%$. Bao-Jie et al. [20] introduced the current situation regarding energy consumption in rural areas in China, and then noted the problems and challenges in achieving energy efficiency in rural buildings. Measures for reducing the rural energy consumption were proposed based on adaptation to local conditions, including measures based on architectural planning and design, building envelopes, the development and utilization of renewable energy, and energy conservation in daily life. Finally, based on the above analysis, suggestions were proposed regarding policies and standards for improving building energy efficiency. Ronald et al. [21] conducted an extensive literature review on the quantitative energy demands of rural areas in developing countries to study 
the energy demands and consumption; they determined the various energy requirements and analyzed their typical consumption levels. Weishu et al. [22] proposed a novel passive heating design method called the "On-Top Sunspace" for solving rural heating problems in the severely cold regions of northern China. The results showed that when the roof angle was $28^{\circ}$ and the front and rear roof glass-to-roof ratios were 0.5 and 0.6 , respectively, the lowest building energy consumption was achieved. Boccalatte et al. [23] used an urban weather generator tool to study the urban heat island phenomenon. The temperature of an urban canyon was calculated based on the location of the city and the geometric shape of a region corresponding to the three European climate zones. The results showed that the urban temperature rose from $0.8^{\circ} \mathrm{C}$ in winter to $2.0^{\circ} \mathrm{C}$ in summer. When using rural weather data as input, the annual air conditioning demand was underestimated by 10\%. Meng Li et al. [24] used rural household survey data from 2005 to 2008 to estimate the proportion of natural gas relative to China's rural energy expenditures, based on the generalized Roy model. The results showed that if the penetration rate of natural gas was doubled, households' fuel expenditures would increase by at least $80 \%$, which could potentially worsen the economic situations of poor households.

The passive renovation of buildings is an effective approach to reducing building energy consumption. Through effective use of the surrounding environment of a building, the transformation of some components of the building can make it more efficient to use naturally generated renewable energy, which is the main means for passive energy saving [25]. For example, the heat transfer rate of the outer wall of a building can be improved by changing the wall material or wall structure [26]. The thermal comfort and ventilation efficiency of a building interior can be improved by using the surrounding environment of the building [27]. In one study, a glass roof was used to increase the heat storage of a courtyard during winter [28].

Aiming to provide a passive design based on the insulation of a building's exterior wall, Ravi et al. [29] studied a novel wall design that included a phase change material (PCM) layer between two layers of a dynamic insulation material and system (DIMS). In all of the climates and wall orientations studied and analyzed, compared with walls integrated with only DIMS or PCM alone, the walls integrated with PCM-DIMS had higher energy-saving potential. Depending on the climate, a wall integrated with PCMDIMS could reduce the annual heat gain by $15-72 \%$, and the annual heat loss by $7-38 \%$. Lili et al. [30] used the "Designer's Simulation Toolkit" energy simulation software to analyze the impacts of the material type and thickness of the external wall insulation layer on building energy consumption in the analysis of a life cycle cost. The economic costs of different insulating materials were studied based on modeling. The results showed that after adding thermal insulation materials to the building envelope, the impact on the cooling load of the building within one year was small, but the impact on the heating load was significant. In the original case, the heating load was reduced by $21.52 \%$, accounting for $3.78 \%$ of the total load. Jinbo et al. [31] proposed a new concept called exhaust air insulation (EAI). The main components of the EAI wall were porous materials providing ventilation performance through a ventilation cavity and external enclosure structure. The research results showed that when EAI was used, compared with brick walls, the total heat increase in the EAI walls in summer was reduced by $84.7 \%$; compared with external insulation walls, it was reduced by $67 \%$. The heat storage performance of the wall was greatly reduced by using a thick porous layer and increasing the wind speed. When the wind speed was $0.003 \mathrm{~m} / \mathrm{s}$ and the thickness of the porous layer was $50 \mathrm{~mm}$, the heat flux of the indoor equipment was almost zero [32]. To explore cost reductions of the exterior wall of the building and reduce the energy consumption, the best thermal insulation materials of different thicknesses were set for the walls, and space was set in the walls to introduce external air into the walls. The results showed that compared with ordinary walls, the energy consumption was reduced by $65-77 \%$ under the influences of air gaps with thicknesses of 2,4 , and $6 \mathrm{~cm}$ and identified the optimal thicknesses of different insulating materials. 
In terms of the rational use of the surrounding environment for passive energy-saving in buildings, Fang'ai et al. [27] proposed a new energy-saving design scheme based on using the evaporation of a water system and a glass roof to passively cool and heat courtyard buildings in the Jiangnan region of China. They also improved the lighting capacity of the building and reduced the energy consumption of the lighting. After the design was combined with air conditioners, the total annual energy consumption for one year was $19,528.88 \mathrm{kWh}$, a saving of $5839.57 \mathrm{kWh}(23 \%)$ relative to the original case. The design functions for passive solar buildings were proposed by Chandel et al. [33], including changing the building layout, transforming the shading efficiency of the windows, and using solar heating to generate indoor cross-ventilation. Using a local thermal comfort standard as a reference, the e-Quest simulation software was used to simulate the effects of the equipment on cooling and heating, and the reduction in energy consumption was calculated. In winter, the suitable operating temperature range for the device was $15.0{ }^{\circ} \mathrm{C}$ to $17.7^{\circ} \mathrm{C}$. Dnyandip et al. [34] classified the passive cooling technologies of buildings in detail and introduced their functions, application scopes, and latest development statuses. They indicated how the cooling load and room temperature affected the passive cooling technology. The results showed that the reasonable use of passive cooling technology could ensure the indoor thermal comfort of the building, while effectively reducing the indoor cooling load. Ahmed et al. [35] used specific experiments and numerical studies to reset a residential ventilation rate and solar chimney design parameters and determined the relationship between the earth-air heat exchanger geometric specifications, pressure, and climatic conditions. Taking Egyptian houses as the main research object, they simulated passive cooling, heating, and ventilation of the rooms. Based on a "TRNSYS" simulation, they found that this correlation could be used to calculate the indoor temperature and load, making it easier for buildings to reach the conditions required for thermal comfort and reducing the building energy consumption and carbon dioxide emissions. Vaseghi et al. [36] proposed a new ventilation strategy for museum buildings based on combining active and passive ventilation so as to comprehensively improve the ventilation efficiency of a museum and used a computational fluid dynamics simulation to verify it. The results showed that even on the coldest day of winter, the building could still meet the temperature requirements for thermal comfort.

Regarding the passive ventilation of buildings, P.M. Sivaram et al. [37] proposed a passive device that used solar energy as the main source of power for passively generating power and improving the ventilation efficiency. The system consisted of a solar photovoltaic system including a chimney and solar distiller. Based on experiments, and using the heat energy obtained by the new equipment, the indoor air was found to change an average of 12 times per hour. The average daily air intake speed as measured on the window was $0.14 \mathrm{~m} / \mathrm{s}$. Compared with an independent photovoltaic system, the electrical efficiency of the photovoltaic system in the building-integrated passive solar energy technology increased from $4 \%$ to $17 \%$. The solar static performance of the integrated system increased from 3\% to 11\%. Abayomi et al. [38] proposed a new type of solar chimney system for improving the ventilation efficiency of tropical buildings, meeting the corresponding thermal comfort requirements, and managing energy reasonably. It was determined that the new system, as combined with solar chimneys, had an indoor impact in a wellventilated state. Under the action of the new system, the indoor wind turbines were controlled to change the airflow rate. Rongpeng et al. [39] proposed that a variable air volume system could be used to dynamically optimize night ventilation (NV) and active building air conditioning in an integrated operation. They established a physical model based on differential-algebraic equations, introduced a configuration method to form a nonlinear program, and then used the "General Algebraic Modeling Language" platform to process the solver using the "Interior Point Optimizer." The research results showed that relative to the scheme without NV, using this method could save $23.19-49.31 \%$ of the energy consumption under different climatic conditions and could save $14.97-39.70 \%$ of energy consumption relative to the NV scheme. 
After a glass roof receives direct solar radiation in winter, it can effectively enhance the heat storage capacity of the courtyard, and the heat stored in the courtyard can be used to heat rooms adjacent to the courtyard [40]. Qianjun et al. [41] built a double-slope hollow glass roof and experimentally studied the heat transfer performance of this device under the influence of different slopes in summer and winter. The results showed that the roof slope affected the indoor roof temperature. When the slope of the roof was reduced from $45^{\circ}$ to $30^{\circ}$, the temperature of the indoor roof surface was reduced by $12.2 \%$. Zhitong et al. [42] applied a transparent radiant cooling film (T-RC) on a roof glass, which has a low transmittance in the solar spectrum and a selective high emissivity in the atmospheric window $(8-13 \mu \mathrm{m})$, to reduce a building's energy consumption. The results showed that by combining the cooling effect of the T-RC film in summer and the heating cost in winter, the annual AC energy consumption of an exhibition hall could be reduced by $40.9-63.4 \%$, according to different environmental conditions. Dong et al. [43] proposed that PCMs could be used to fill glazed roofs and compared such roofs with normal glazed roofs. PCM melting temperature and PCM/glass roof slope tests were conducted, with different thicknesses for the elements. The results showed that the maximum energy saving was $47.5 \%$ with the use of the new materials.

In previous studies, various methods have been developed for reducing the energy consumption of buildings and to achieve certain results. However, these methods still have problems that need to be solved. The renovation of an exterior wall mainly involves the use of new materials for replacement. Most new building materials are only in the experimental stage and cannot be popularized in time. The transformation of exterior walls also mainly involves the use of new materials for replacement. The time and cost for producing such materials must be further optimized [44]. Moreover, in terms of passive ventilation and cooling design, these materials must be combined with air conditioning. Most of the new equipment still require non-recyclable energy, and therefore, cannot be called completely passive [45]. Other methods merely consider the energy-saving effect of a glass roof, without considering the rationality of the installation and the difficulty of construction [46]. In addition, many technologies mainly focus on urban architecture, and some of them are not applicable to traditional residential buildings. Other passive energy-saving technologies mainly take part of the building as the research object, and there is a lack of relevant research on comprehensive operations [47]. Another shortcoming is that the influence of wall heat radiation (WHR) on the interior is ignored in most of the research processes [48].

\subsection{Scientific Originality}

We have previously proposed a new passive optimization strategy for rural houses combined with cold alley cooling and energy saving and introduced the basic working principle and operating mechanism of a cold alley [49].

However, this study has added new energy-saving equipment on the basis of [49]. Combining passive energy-saving technology, including cold alleys, with other technologies comprehensively analyzes the efficiency of cooling, ventilation, and energy saving and saves as much energy as possible and takes advantage of passive energy saving as the main purpose.

Firstly, the heat transfer process of the wall in the previous study was analyzed and discussed. We aimed to slow down the wall heat transfer rate in summer and accelerate the heat dissipation of the wall; a thin wall was added along the outer wall of a building, and space was reserved in the middle. The cold air from a cold alley was stored in the space, thereby forming an air wall. The principle was similar to that of a thermos cup, which blocks direct contact between a high-temperature wall and a room. The cold air from the cold alley in the wall could also be used to dissipate the heat generated by the wall receiving solar radiation. The materials used in the new walls were all basic building materials, and no new PCMs were used. 
Secondly, the indoor areas and cold alleys were connected to the newly built walls, and air ducts were used to connect the rooms on both sides of the patio. Hot pressure ventilation, the accumulation effect of the patio, and the chimney effect were used to guide the cold air from the cold alley into the room. The cold air from the cold alley could not only lower the indoor temperature, but could also promote air circulation and speed up the air exchange rate in the room. Based on taking the WHR as an independent parameter, a systematic analysis and comparison of whether to consider the WHR status was conducted. This verified the importance of the influence of the WHR on the indoor thermal environment during summer.

Finally, in winter, the air ducts connecting both sides were used as supporting members for adding a glass roof above the courtyard to improve the heat storage capacity of the patio. Solar radiation continuously heated the patio. After a period of time, the patio could transfer heat to the rooms of the building, thereby increasing the indoor temperature. Thus, at this time, the patio was equivalent to a constant-temperature heater. Compared with the cooling and energy saving of separate cold alleys [49], this new system combined four functions, i.e., insulation of the building exterior wall, indoor cooling in summer, an increased ventilation rate, and indoor heating in winter. In addition, it did not use any non-renewable energy. It was a completely passive design in the true sense, as for the first time, a cold alley between buildings was used as the source of cooling and ventilation. This study can reduce the heating and cooling load of the building more than the previous research [49], and raise the efficiency of indoor cooling and ventilation to a new level. This system integrated mainstream passive energy-saving technologies from recent years and comprehensively applied them to traditional residential buildings, filling the gaps in the comprehensive application of passive designs to rural courtyard houses.

\subsection{Targets of This Research}

To reduce the energy consumption of traditional residential buildings and improve the living comfort of residents, this study designed a new type of passive energy-saving system. After conducting a multi-faceted comparative analysis of the basic case and of traditional houses after the new system had been added, the following points were considered as the specific objectives of the study:

- By comparing the effects before and after adding thermal insulation walls in traditional residential buildings, we estimated the annual cooling load reduction from using thermal insulation walls in summer.

- The cooling effects of a base case and of a building using the passive system were examined without considering the WHR, aiming to calculate the cooling efficiency inside the building, thermal equilibrium temperature, and reduction of the cooling load for the entire building throughout the year.

- The cooling effects of the new system with and without WHR were compared, in addition to the room cooling rate, thermal equilibrium temperature, and annual cooling load reduction for the entire building.

- Based on comparing the heating effects of a courtyard with or without a glass roof in winter, we estimated the time required for a patio to meet the required heating conditions and reduce the total heating load throughout the year.

- The appropriate utilization time for the new passive system over a year was calculated.

- According to a local comfort temperature standard, the annual time required to meet the comfort temperature requirement for the base case was estimated, and the annual times required to meet the comfort temperature standard after using the new system with and without WHR were compared. 


\section{Methodology}

\subsection{Investigation Study}

\subsubsection{Geographical Location and Weather Conditions}

Shuhe is located in the eastern mountainous area of Xunyang County, Shaanxi Province $\left(32.9357^{\circ} \mathrm{N}, 109.7037^{\circ} \mathrm{E}\right)$, with an area of approximately $143.5 \mathrm{~km}^{2}$ and township area of $3.3 \mathrm{~km}^{2}$. Its terrain is a hilly landform on the southern slope of the Qinling Mountains. Shuhe is located on the northern edge of a subtropical climate and belongs to a typical transitional zone of China's north-south climate. There is plenty of precipitation in the territory (with an average annual precipitation of approximately $800 \mathrm{~mm}$ ), mostly concentrated in summer and autumn. Owing to the concentration of precipitation in summer and autumn and the frequent convergence of the Indian Ocean and Pacific monsoons, coupled with the uplift of the terrain, heavy rains and rainstorms are easily formed. Figure $1 \mathrm{~b}$ shows the dominant wind direction and maximum wind speed in Shuhe. The dominant wind direction is from southwest to northeast, and the maximum wind speed reaches 6-7 m/s. Figure 1c shows the outdoor temperature of Shuhe Town in 2019. The annual average temperature is $17^{\circ} \mathrm{C}$, the highest temperature is $38.7^{\circ} \mathrm{C}$, and the lowest temperature is $-4.45^{\circ} \mathrm{C}$. It has a northern subtropical climate.

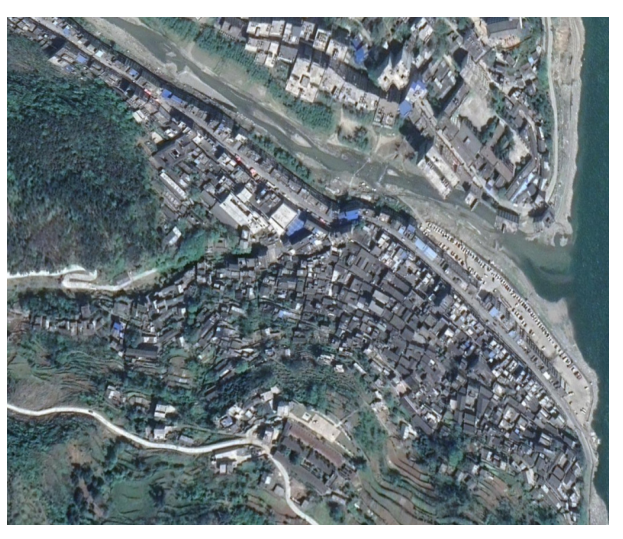

(a) Topographic map of Shuhe.

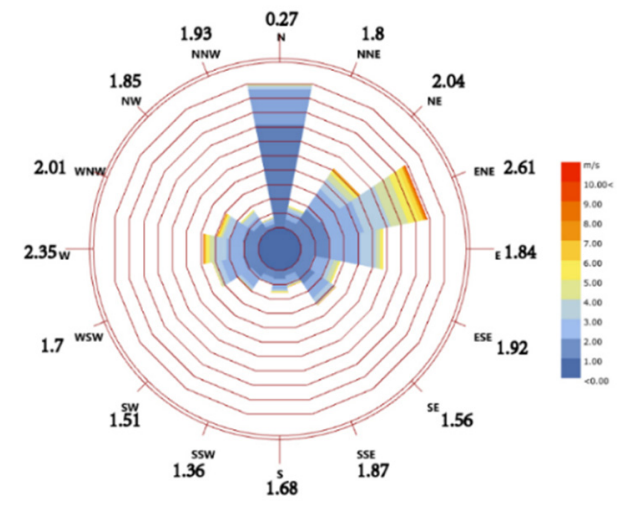

(b) Dominant wind direction and maximum wind speed.

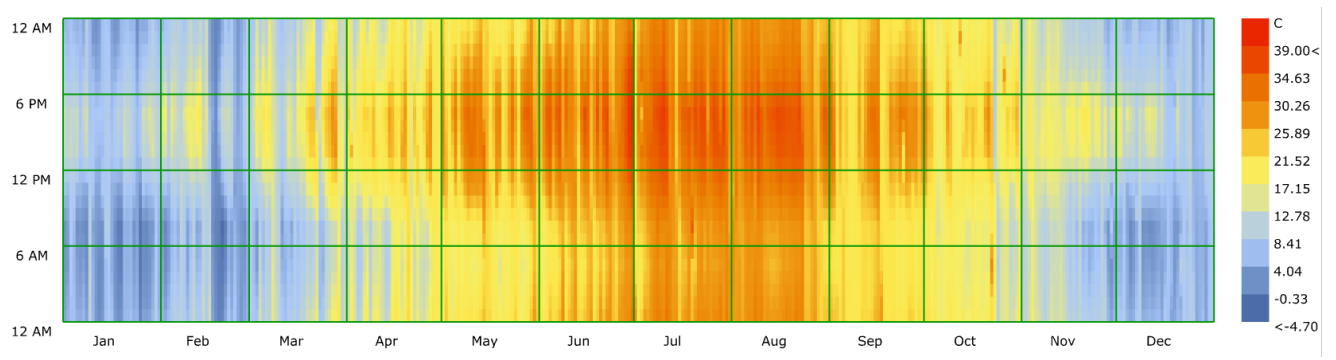

(c) Outdoor temperature throughout the year.

Figure 1. Geographical location and climate information of Shuhe.

\subsubsection{Case Study Information}

The method for selecting research cases mainly consisted of the following processes:

- Field investigation: The different forms of traditional houses in the village were collected and sorted, and representative buildings related to the study were selected.

- Measurement of related data: The data of these traditional houses were measured, including the size of the building, positions of doors and windows, indoor and outdoor temperatures and wind speed, outer surface temperature of the building, and angle between the dominant wind direction and building. 
- Summarizing and organizing the data: After the measured data were unified and integrated, the most representative data were used for the case study.

- Problem confirmation: It was found that the temperature in the cold alley around the building was generally lower than the normal outdoor temperature. After analyzing the measured data of the case study, it was found that the indoor thermal environment and ventilation efficiency in the building required improvement.

- Countermeasures: After analyzing and researching a cold road in the village, we considered how to use the cold air in the cold alley to cool the building and improve the ventilation.

Figure 2a shows the basic case of this research, which is an enclosed courtyard surrounded by four two-story buildings. The height of the first floor in all buildings is $3 \mathrm{~m}$, and the height of the second floor is $2.8 \mathrm{~m}$. The courtyard space is $9.2 \mathrm{~m}$, and the depth is $22.9 \mathrm{~m}$. The outer retaining wall is a blue brick masonry structure, and all of the buildings have sloped roofs. A sloped roof can play a role in shading and drainage. This is a typical Chinese traditional arrangement centered on the courtyard, and the courtyard is representative of those in Shuhe.

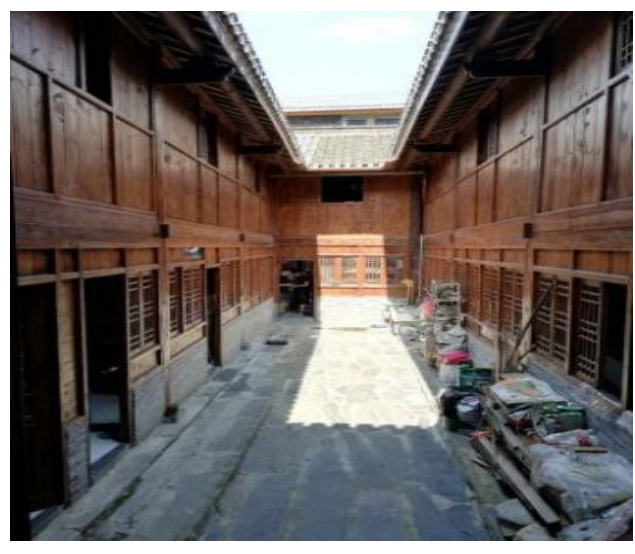

(a) Research case situation.

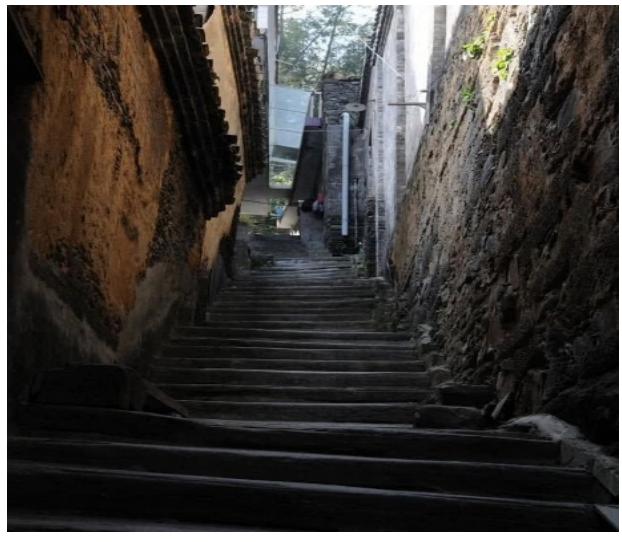

(b) Situation in a cold alley.

Figure 2. Research case and cold alley.

Shuhe is mainly composed of ancient buildings from the Ming and Qing dynasties. It is $160 \mathrm{~m}$ wide from east to west and $735 \mathrm{~m}$ long from north to south, covering an area of approximately 9.78 hectares. The street node system mainly comprises three levels: main streets, roadways, and street nodes. The streets comprise three vertical main streets and five horizontal lanes, which run through the entire village and town. The layout of the streets and lanes is dominated by broken lines. The laneway and main street intersect vertically, and the laneways are connected to each other by alleys to form a complete street lane system. The middle street, as the main axis, is the core of urban development. The scale of the roadway is relatively narrow, and the width of the narrowest street is less than $2 \mathrm{~m}$, fully reflecting its subordination to the main road. The narrow lanes effectively reduce the traffic volume, allowing the residents in the lanes to obtain a comfortable living environment. The street scale of a traditional building follows ancient heritage and is narrow and compact. Most of the roadways are too narrow, leading to insufficient sunlight, less direct solar radiation, heavy rainfall, and moist ground; these promote the growth of mosses and ferns, and the photosynthesis of such plants can absorb the surrounding heat. Under the comprehensive influences, the temperature in this type of tunnel (which we call the "cold alley") is lower than the outdoor temperature (Figure $2 b$ ). As an auxiliary road, a cold alley comprises high and low pedestrian steps for connecting the main streets as a whole so that the roads of the entire ancient town are connected to a network interconnection system. 


\subsection{Analysis of the Cold Air Storage Capacity in Cold Alleys}

After investigating the local climate and measuring the study cases, it is also necessary to analyze the cold air storage capacity of the cold alleys. The ability of cold alleys to store cold air includes two aspects. First of all, considering the narrow size of the streets of the cold alleys, the bottom of the cold alleys does not have the ability to receive a lot of solar radiation, which will cause the temperature of the bottom of the cold alleys to be different from the average outdoor temperature, so it is necessary to analyze its sunshine duration and the intensity of solar radiation. Secondly, the ability to store cold air is also related to the air flow in the cold alleys, so the wind environment in the cold alleys must be analyzed.

\subsubsection{Sunshine and Temperature Analysis in Cold Alleys}

To understand the distribution of streets in Shuhe in more detail and facilitate subsequent research on the solar radiation and ventilation performances of the streets and lanes, in this study, the entire village was roughly divided into different building densities, as shown in Figure 3a. For the four areas, the building densities were 37.14\%, 35.59\%, 35.71\%, and $24.77 \%$, respectively. With the gradual decrease in density, the sizes of the roads and lanes in these four areas were divided into four gradually decreasing levels. To obtain a more detailed understanding of the temperature and ventilation conditions of the streets and lanes at different scales, a total of 30 points were selected as actual measurement points in the streets and lanes of areas with different densities so as to facilitate data comparison and analysis.

Figure $3 \mathrm{~b}$ shows the solar radiation intensity of Shuhe over a year. It can be seen that as the density of the buildings increases, the amount of solar radiation received in the streets and lanes gradually decreases. In the densest areas $(37.14 \%, 35.59 \%)$, the annual solar radiation in the streets and lanes is between $141.07 \mathrm{kwh} / \mathrm{m}^{2}$ and $282.16 \mathrm{kwh} / \mathrm{m}^{2}$. This means that almost all of the streets are in a state of no sunlight throughout the year. Figure $3 c-e$ show the sunshine conditions of the streets and cold alley during a day. It can be seen that there is only a short period of sunshine (from 12:00 to 13:00) in the day, and that the area receiving solar radiation is only $1.58 \mathrm{~m}^{2}$. The temperatures of the cold alley and outdoor air are the closest at 5:00 in the morning, at approximately $26.2^{\circ} \mathrm{C}$. With the passage of time, the difference between the two temperatures increases, reaching a peak at 17:00. At this time, the temperature in the cold alley is $33.1^{\circ} \mathrm{C}$ and the outdoor normal temperature is $38.8^{\circ} \mathrm{C}$; thus, the difference reaches $5.7^{\circ} \mathrm{C}$ (Figure 3f). 

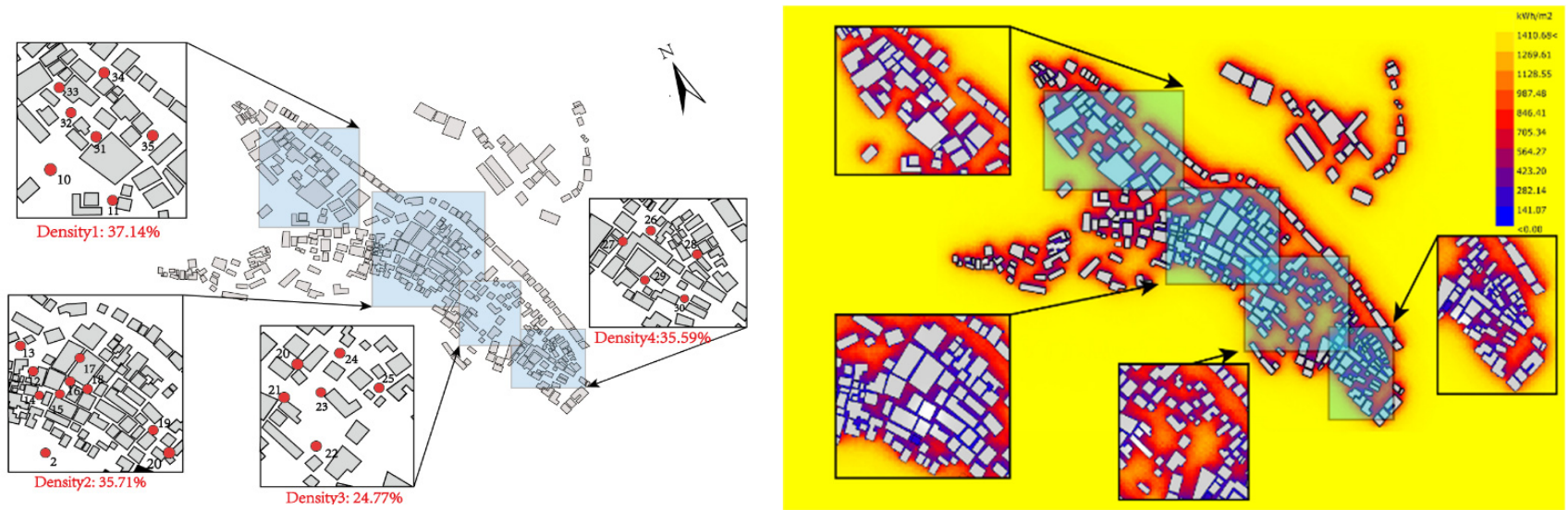

(a) Building density zoning of the main village.

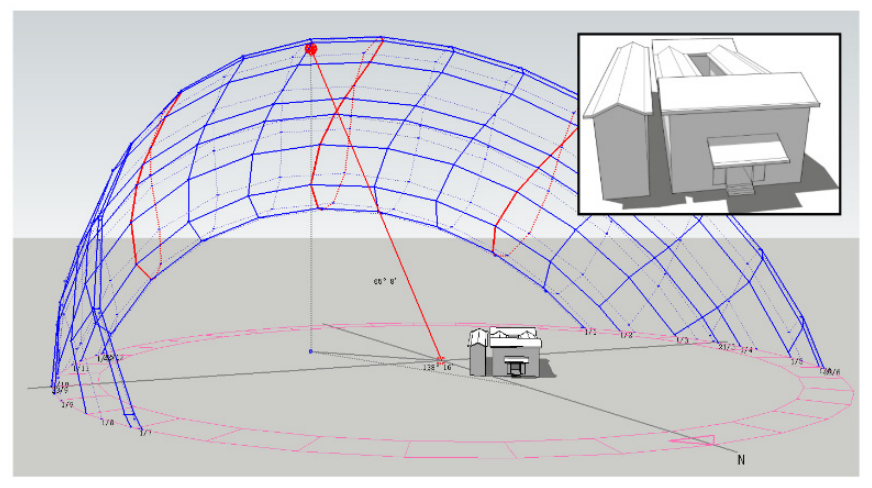

(b) Village solar radiation analysis.

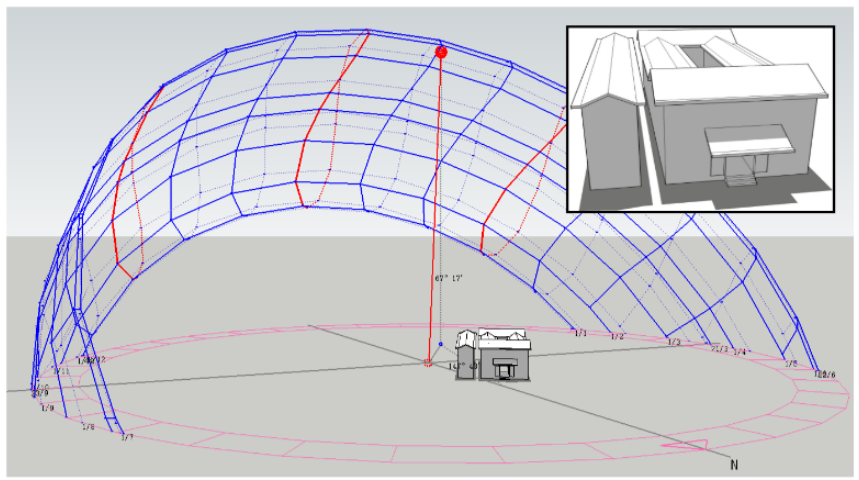

(c) Daylighting in the cold alley at 11:00.

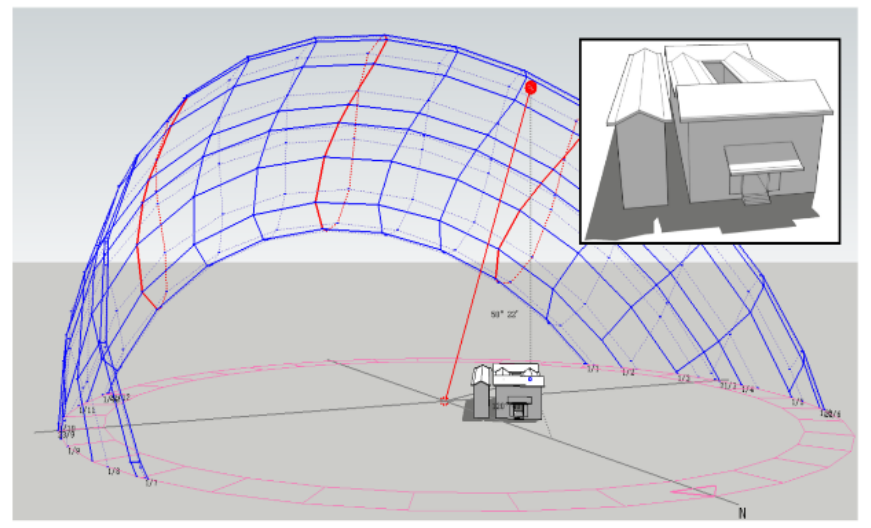

(e) Daylighting in the cold alley at 13:00. (d) Daylighting in the cold alley at 12:00.

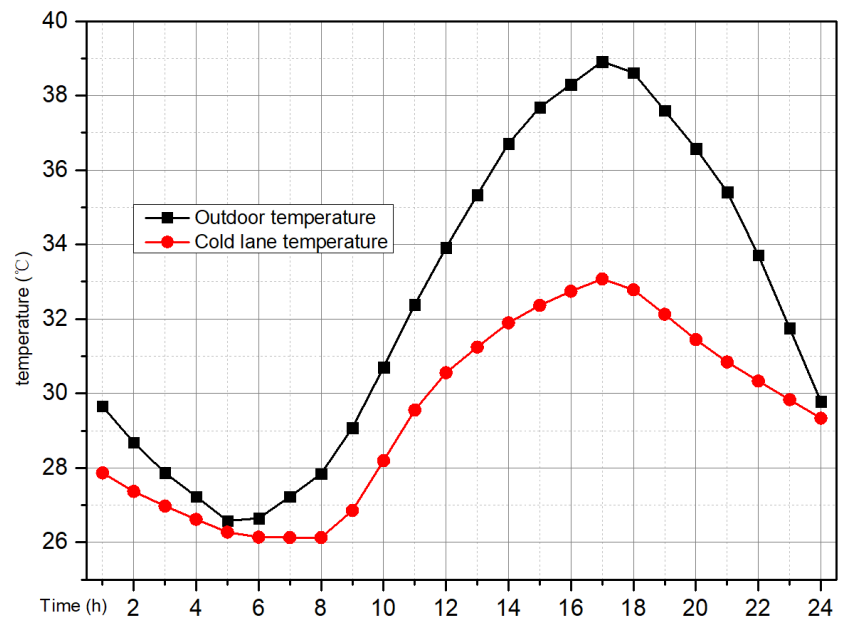

(f) Comparison of cold alley temperature and outdoor normal temperature.

Figure 3. Analysis of solar radiation and temperature in the cold alley.

\subsubsection{Ventilation in the Cold Alley}

The reasonable use of natural ventilation is a very important method for the passive ventilation and cooling of buildings. This can increase the ventilation frequency in the building, reduce the temperature, and improve the comfort of residents; moreover, it can also save a certain amount of energy consumption. Therefore, in this study, the cold air 
in the cold alley was introduced into the building rooms, and street ventilation values of different sizes of streets were analyzed. As shown in Figure 4, the airflow velocity in the streets is positively related to the size of the street, as the air is blocked by other surrounding buildings. In the narrowest street (cold alley), the wind speed is only $0.147 \mathrm{~m} / \mathrm{s}$. Because there is no horizontal airflow, the cold air in the cold alley is not easily lost, showing that the cold alley has good heat insulation and that the main method of air flow is hot pressure ventilation. Hot pressure ventilation can be used as a necessary condition for the passive cooling of buildings. Moreover, as the air flow accelerates, the ventilation efficiency in the room will also be greatly improved.

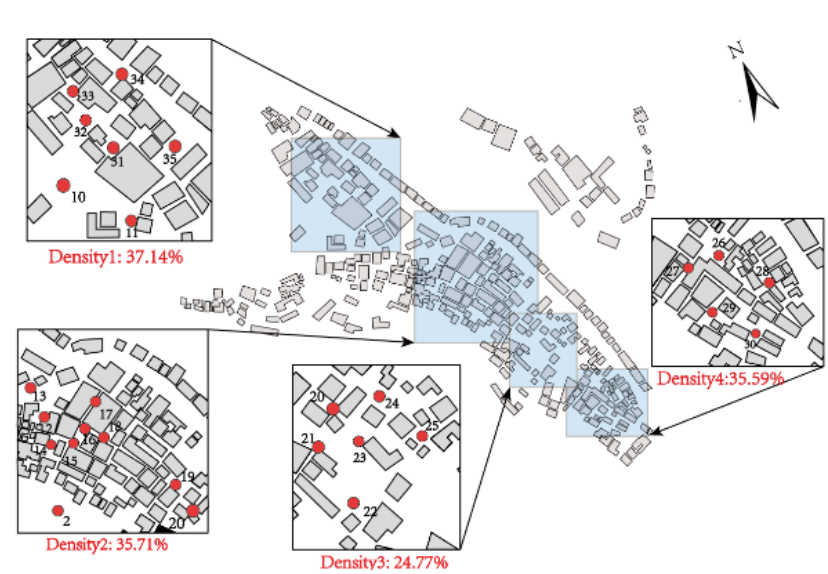

(a) Building density zoning of the main village.

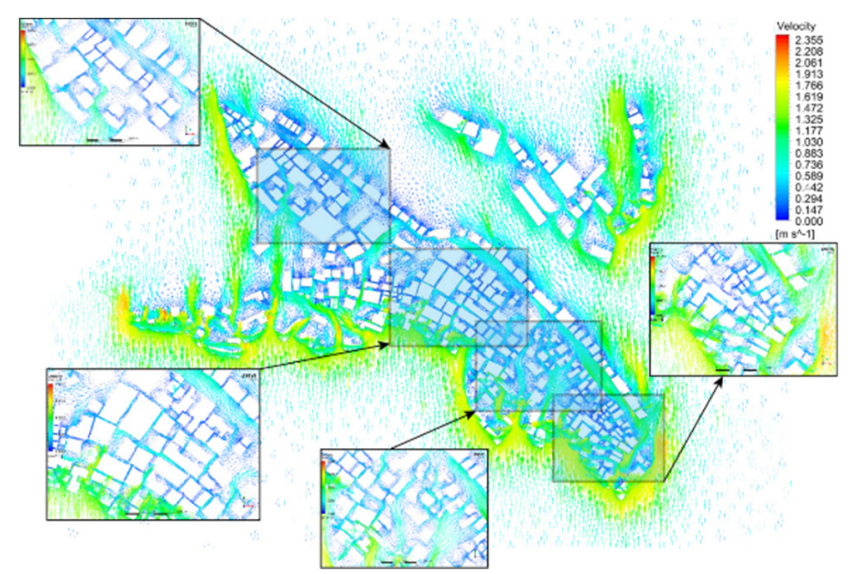

(b) Ventilation situation of different streets.

Figure 4. Ventilation analysis of village streets.

Through actual measurements of the various data of the case study and analysis of the laneways of different widths in the village, it was concluded that the cold alleys received a small amount of solar radiation during the annual sunshine period; thus, their temperatures were lower than the normal outdoor temperature. Owing to the hindrances of other buildings in the village, the horizontal ventilation capacity was weak, so the cold air in the alley could be preserved.

\subsection{Transformation of the Original Case}

If the cold air in the cold alley could be introduced indoors using a passive method, the hot pressure ventilation method could be considered; accordingly, the temperature difference between the cold alley and building indoors was used for the indoor and outdoor heat exchange. Simultaneously, the patio of the building was connected to the interior through doors and windows, and the accumulation effect of the patio air was combined with the cold air to form a new integrated passive ventilation and cooling system. While introducing the cold air, the rooms on the second floor on both sides of the courtyard were connected by pipes to provide more efficient cooling. Notably, most of the previous studies on air heat transfer did not consider the heat radiation from the exterior surface of the building. The influence of this heat radiation on the indoor temperature cannot be ignored. Therefore, in this study, the presence or absence of WHR was specifically cited as a separate item, aiming to show its degree of importance. In addition, in winter, the pipes for connecting indoors could be used as supports, i.e., to facilitate the installation of glass roofs. After adding a glass roof above the patio, the patio would store a significant amount of heat after receiving solar radiation, and could then transfer this heat through the doors and windows to heat a room. The new system mainly covered three aspects of passive design. In summer, air partition walls were used to block the direct heat transfer between the exterior surface of the building and interior. Hot pressure ventilation was used to introduce cold air from the cold alleys into the rooms, to provide passive cooling, 
and to improve ventilation. In winter, the glass roof was used to improve the heat storage capacity of the patio so as to ultimately increase the indoor temperature. The introduction to the transformation of the study case is divided into the following four parts:

- Introduction of basic study case, which will be compared with the reconstructed building.

- Analysis of the operation principle of heat transfer of the heat insulation wall in summer. It is mainly used to introduce the cold air in the cold alley into the room and slow down the heat transfer.

- Introduction of the operating principles of the new system when the wall heat radiation is considered and when the wall heat radiation is not considered.

- After adding a glass roof above the patio in winter, analysis of the heat storage capacity of the courtyard and the operating principle of heat transfer to the room.

\subsubsection{Natural Ventilation Cooling (Base Case)}

The heat transfer and ventilation methods for the base case are shown in Figure 5. The overall building mainly relies on the ventilation from the patio for improving the temperature of the building. The outdoor air first enters the patio through the gate, circulates to a certain extent, and is discharged from the top of the patio. At this time, the indoor temperature is higher than the courtyard temperature, and a small part of the heat is exchanged through the doors and windows. However, as shown in Figure $5 c$, the entire process of ventilation and heat exchange mainly occurs in the patio, and the improvement in indoor temperature is very small, or even negligible.

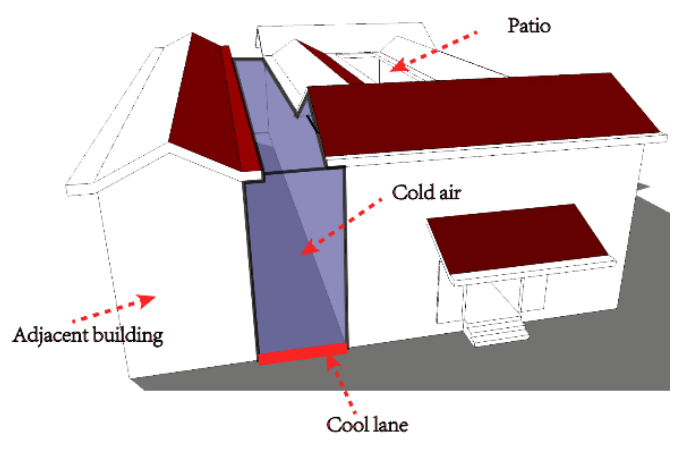

(a) Base case.

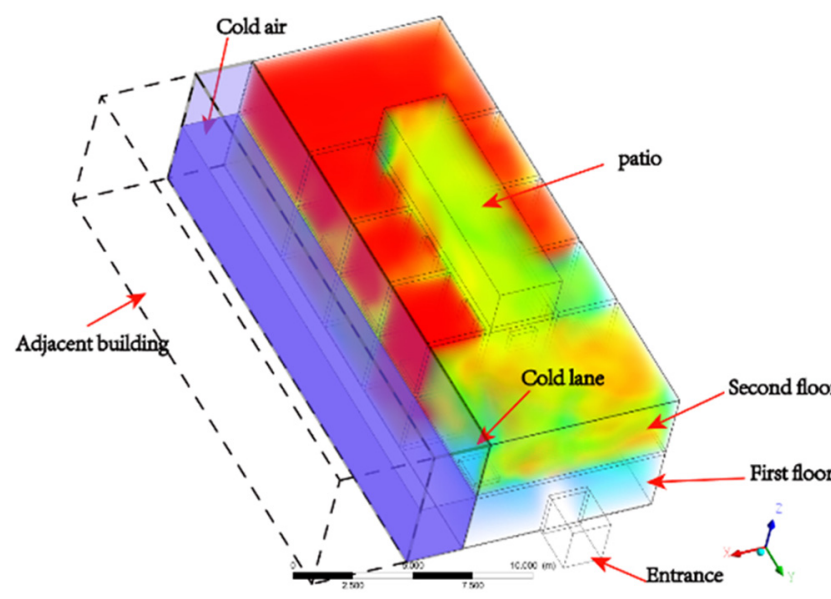

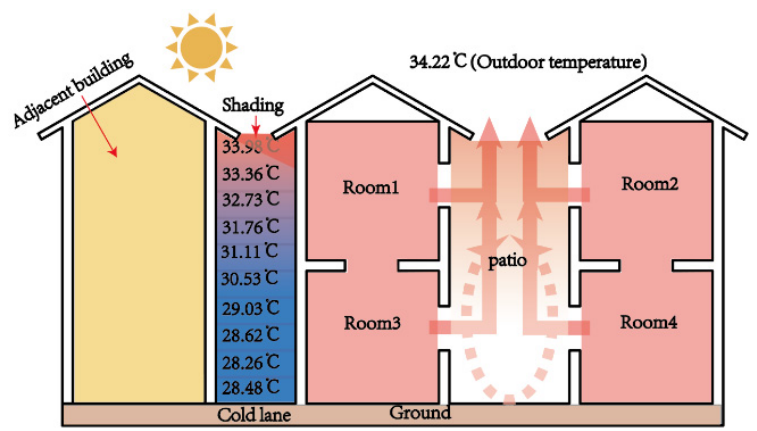

(b) Ventilation and heat transfer conditions before reconstruction.

(c) The heat flow of the building before renovation.

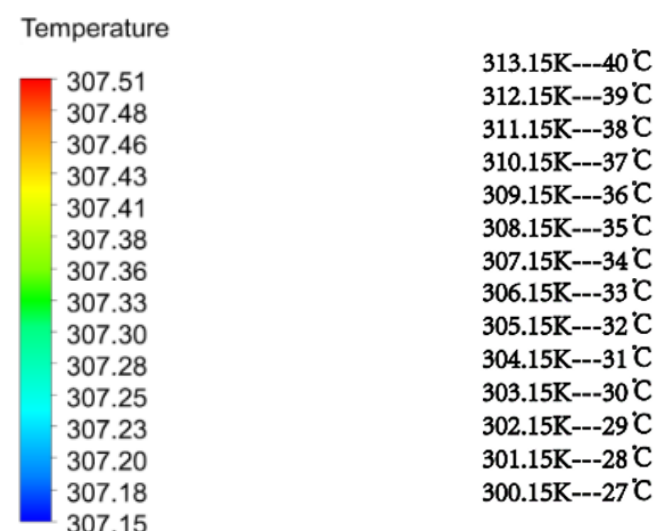

Figure 5. Ventilation and cooling conditions of the original case. 


\subsubsection{Summer Air Insulation Wall}

In summer, the outer surface of a building is exposed to the sun for a long time, and the amount of received solar radiation is large. This radiation is transmitted through the wall materials and is an important cause of the increase in the indoor temperature. If a barrier can be set on the outside of the wall to hinder the transmission of heat, the growth rate of the indoor temperature will be significantly reduced. As shown in Figure 6a, in this study, the air wall was constructed as an important part of the new system and provided three main functions. First, it was used as a carrier to introduce cold air from the cold alley into the building interior, playing a role similar to that of a pipe. Second, the cold air could be stored in the wall for a long time, which could cool down the interior wall to a certain extent. Finally, the air wall was used as a barrier to hinder the heat transfer between the outer and inner walls. The principle was similar to that of an "insulation cup," but the function of an insulation cup is to preserve the loss of internal heat, which is the opposite of the function of the air wall in this study. Figure $6 \mathrm{~b}$ shows the heat transfer of the indoor wall before and after installation of the air wall in the building. It can be seen that owing to the combined action of the three functions mentioned earlier, the amount of radiation on the wall near the cold alley is greatly reduced; in contrast, the wall near the courtyard has no air wall, and the heat radiation effect is stronger. Figure $6 \mathrm{c}$ shows the connection between the air wall and indoor air. The pink part represents the original wall of the building on which and the new system is constructed, and the green part represents the air.

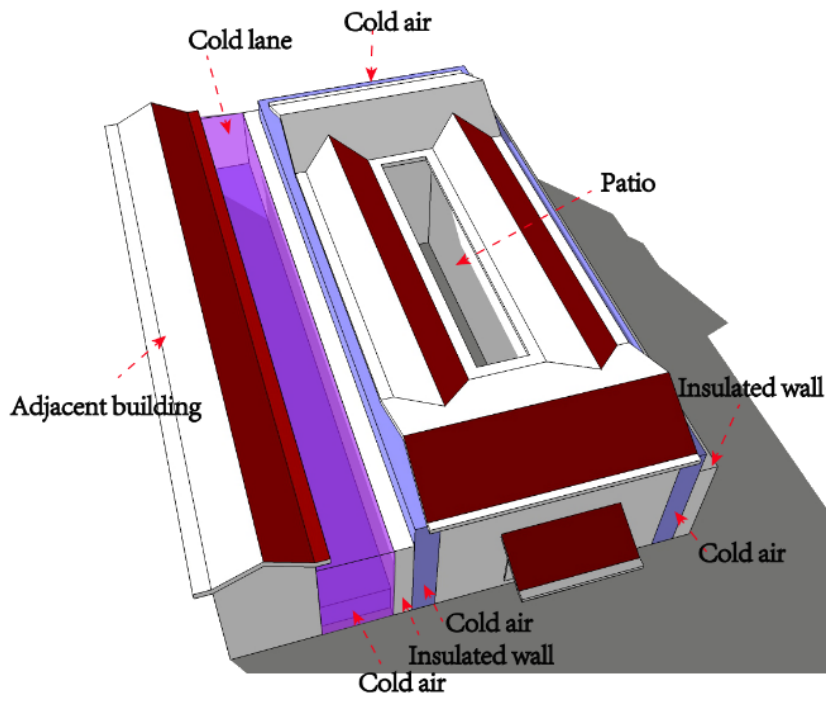

(a) Location relationship between cold alleys, air walls, and buildings.

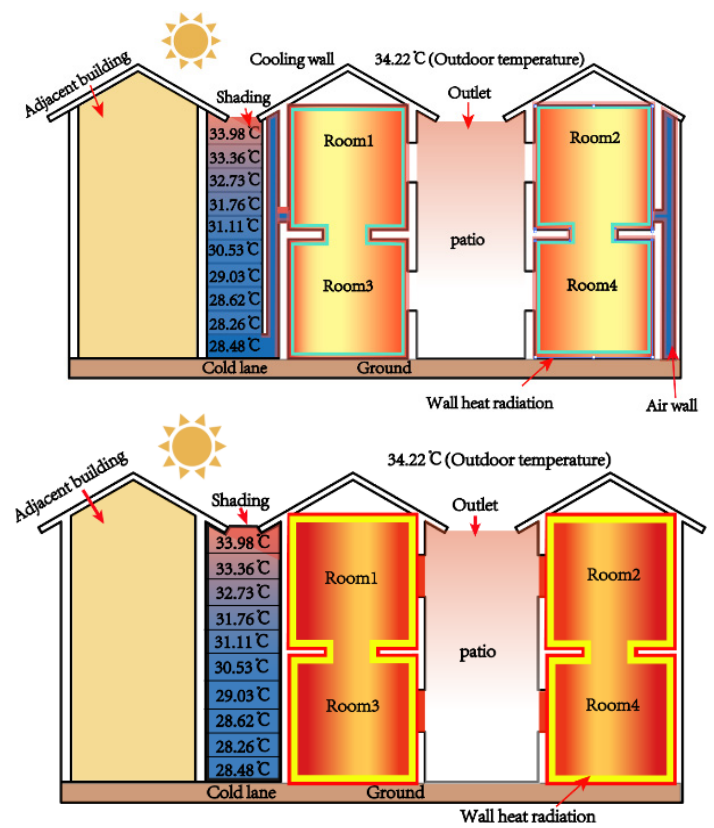

(b) Comparison of indoor heat transfer before and after renovation.

Figure 6. Cont. 

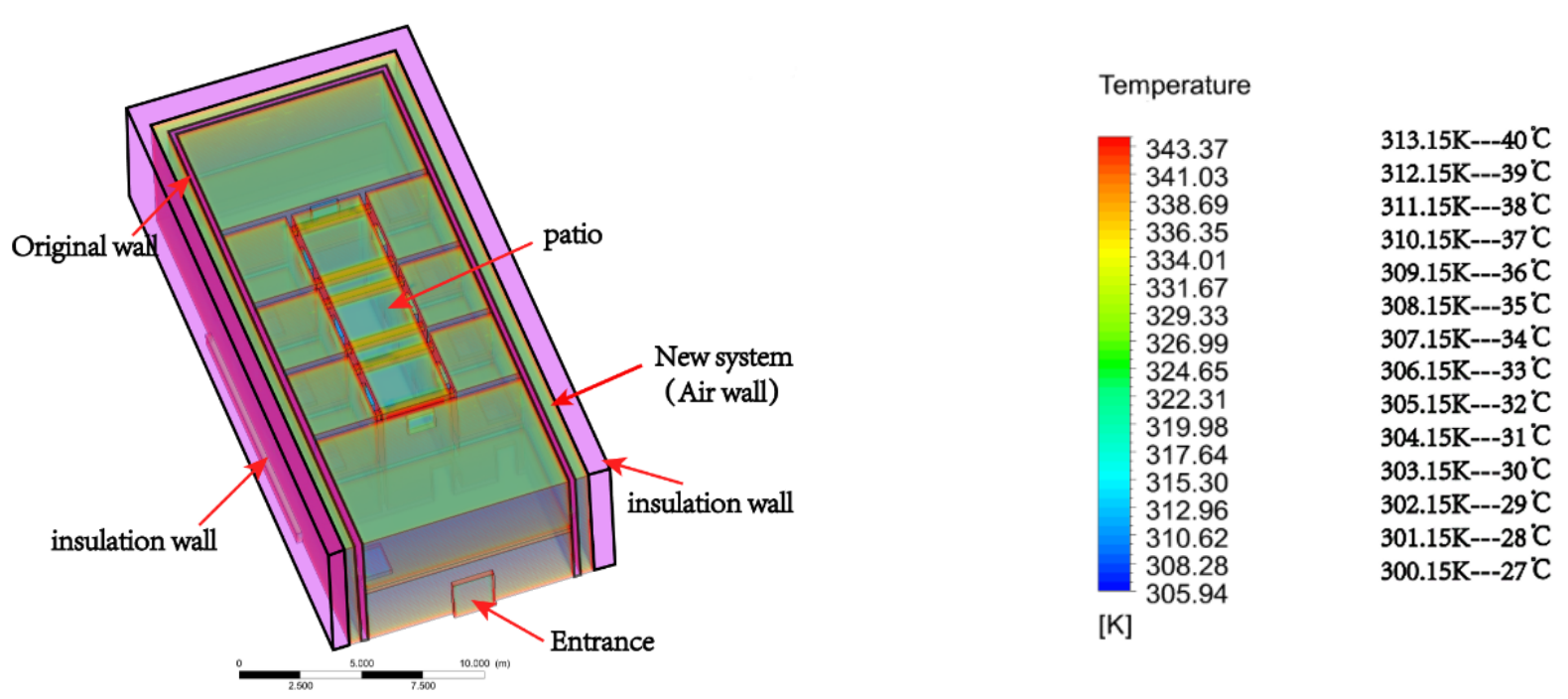

(c) Schematic diagram of air barrier heat resistance.

Figure 6. Introduction of the air insulation wall.

\subsubsection{Using Cold Alleys to Cool Buildings in Summer (without Wall Heat Radiation (WHR))}

Figure 7a shows the positional relationship between the cold alley and building, as well as a schematic diagram of the changes to the exterior wall of the building. First, a new layer of wall was built on the outer wall of the original building, leaving a space in the middle for introducing the cold air. Second, a hole was opened at the bottom of the new wall to allow cold air to enter the space between the walls. Third, the space was connected with the rooms on both sides so as to ensure that the cold air in the cold alley could enter the rooms. Finally, the rooms on the second floor on both sides of the courtyard were connected by air ducts. The purposes of this were to shorten the cooling time and improve the cooling efficiency. The interior and patio were connected by doors and windows. Owing to the difference in the air temperature between the patio and cold alley, a pressure difference arose between the two ends. When the airflow started to move, it was also accompanied by the beginning of the heat exchange process (Figure 7b). It can be seen from Figure $7 \mathrm{c}$ that after the new system was installed, the building had two air intakes: the inherent patio door of the building and the wall hole set by the new system in the cold alley. As mentioned above, under conditions of natural ventilation, the outside air first enters the patio through the patio gate. It only exchanges heat with the room through the doors and windows after it completes the heat exchange in the patio. However, if the cooling capacity of the outside air is not sufficient to cool the patio, the indoor temperature will not be improved. Therefore, as shown in Figure $5 c$, a large amount of air enters the patio first and the temperature drops there first; thus, the cooling gains in the room are minimal. After a period of time, the patio temperature is approximately $34{ }^{\circ} \mathrm{C}$, and the indoor temperature is approximately $35^{\circ} \mathrm{C}$. However, as shown in Figure $7 \mathrm{c}$, when using the new system from this study, the air in the cold alley could directly enter the room for cooling, thereby avoiding the patio and significantly improving the cooling efficiency. Thus, after a period of time, the indoor temperature dropped to approximately $30^{\circ} \mathrm{C}$, whereas the patio temperature was approximately $35^{\circ} \mathrm{C}$. The temperatures in most of the first and second floors were significantly lower than that of the patio. The room near the patio gate was far away from the cold alley and was affected by the higher-temperature air entering from the patio gate. Thus, the temperature drop was not significant, and the air temperature was close to the normal outdoor temperature of $36-37^{\circ} \mathrm{C}$. 


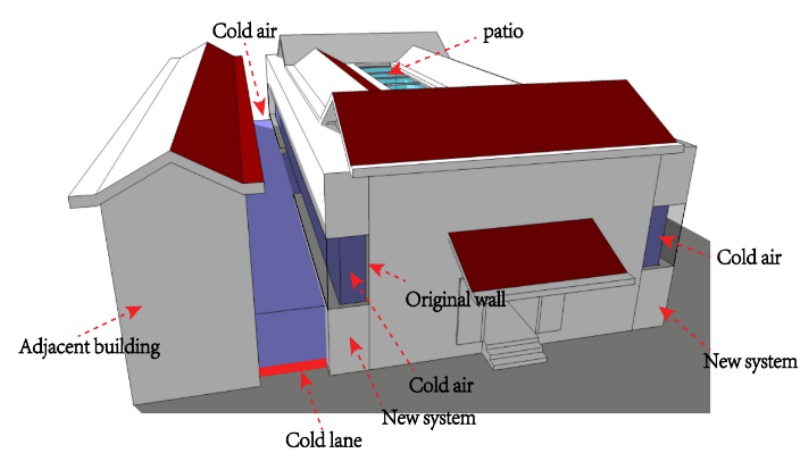

(a) New system settings.

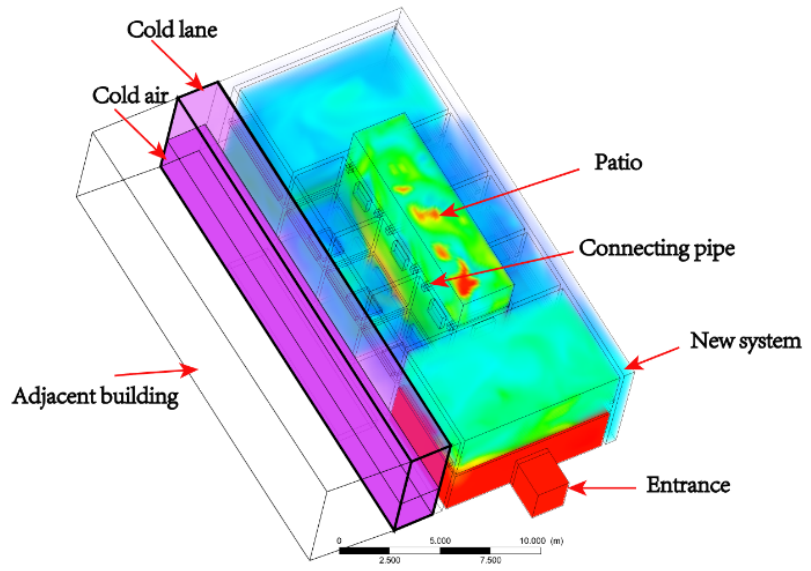

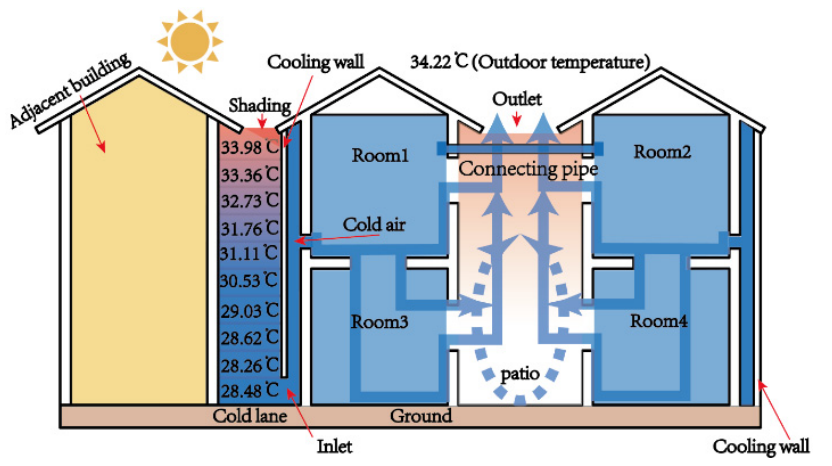

(b) The working principle of the new system (without wall heat radiation (WHR)).

(c) Heat transfer process of new system (without WHR).

Figure 7. Introduction to cooling (without WHR).

\subsubsection{Using Cold Alleys to Cool Buildings in Summer (with WHR)}

If the effect of the WHR on the indoor temperature is considered, the cooling efficiency will decrease. In summer, the outer surface of a building receives direct solar radiation for a long time, and the wall material acts as a medium for heat transfer from the outside to the inside. As shown in Figure 8b, in this study, the heated wall was similar to a constant-temperature source of heat and continuously provided heat to the room from the surroundings of the room. The cold air entering the room from the cold alley was already heated in the space between the two walls, and was also heated by the indoor air when it entered the room; this was an important reason for the decline in cooling efficiency. Therefore, as seen in Figure 8c, the new system still had a significant cooling effect, but it was much inferior to the case without WHR (Figure 7c). After a period of heat exchange, the indoor temperatures of the first and second floors were approximately $32-33{ }^{\circ} \mathrm{C}$. The temperature in the patio was between $36^{\circ} \mathrm{C}$ and $37^{\circ} \mathrm{C}$. The temperature of the room near the courtyard door remained close to the normal outdoor temperature. 


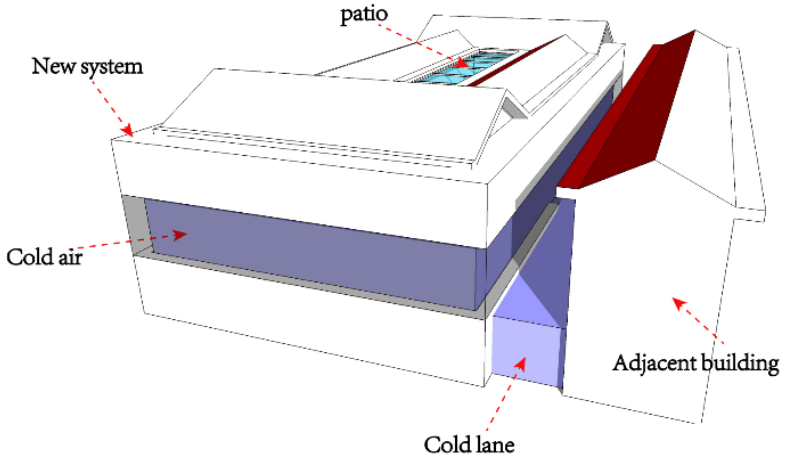

(a) Ventilation system location of the cold alley on the back façade.

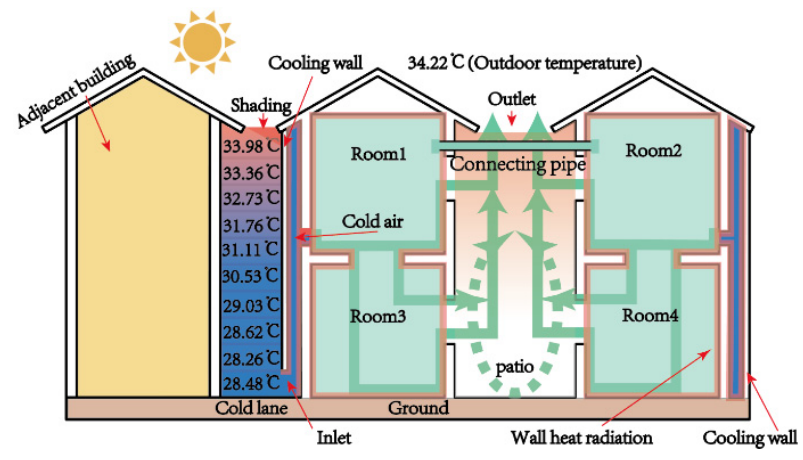

(b) Working principle of the new system (with WHR).

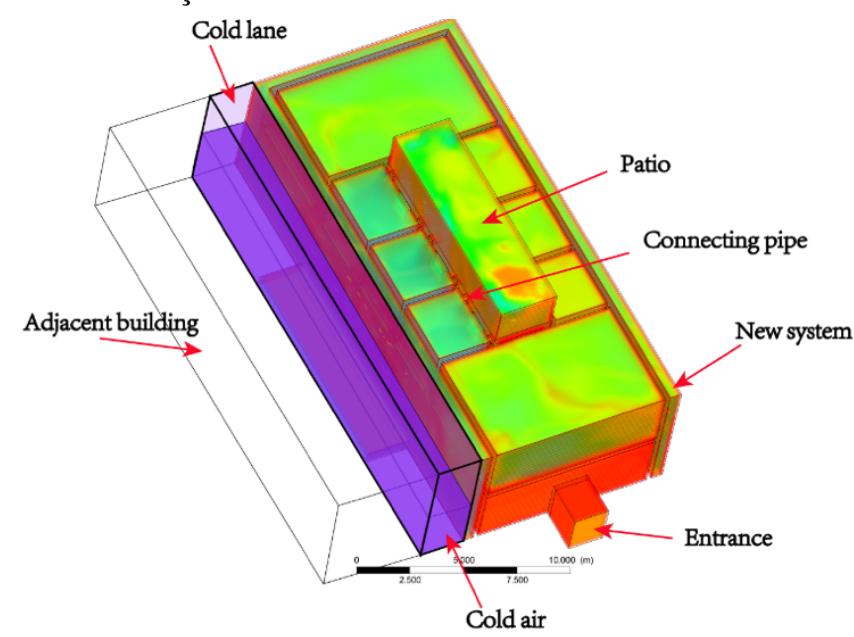

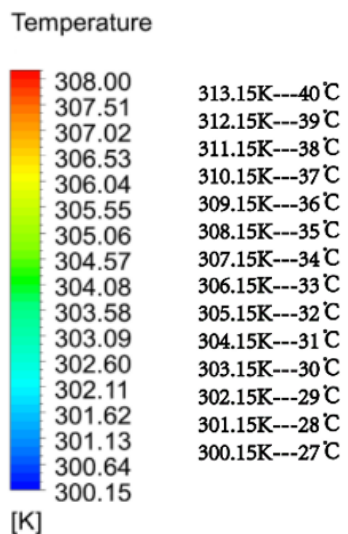

(c) Heat transfer process of the new system (with WHR).

Figure 8. Introduction to cooling (with WHR).

\subsubsection{Installation of the Glass Roof in Winter}

As shown in Figure 9a,b, in winter, the new system uses the interconnecting pipes between the rooms as a support frame to build a glass roof above the patio that can help the patio store heat. As shown in Figure 9c, the courtyard without a glass roof had no heat storage capacity, and the temperature of the patio was basically the same as that of the outdoors. The cold air penetrated into the room through the doors and windows of the room, greatly reducing the temperature in the room. However, after adding a glass roof, the patio had the capacity to store heat. Affected by solar radiation, the air in the patio was first heated from top to bottom, and the temperature was arranged from high to low in the vertical direction. After the patio air was fully heated, it could exchange heat with the low-temperature indoor air through the doors and windows, thereby increasing the room temperature. By comparing Figure $9 \mathrm{e}, \mathrm{f}$, we can clearly see the effect on the courtyard from installing the glass roof. After heating, the courtyard was equivalent to a constant-temperature heater which continuously delivered heat to the room during the day. The courtyard without a roof showed the opposite effect. 


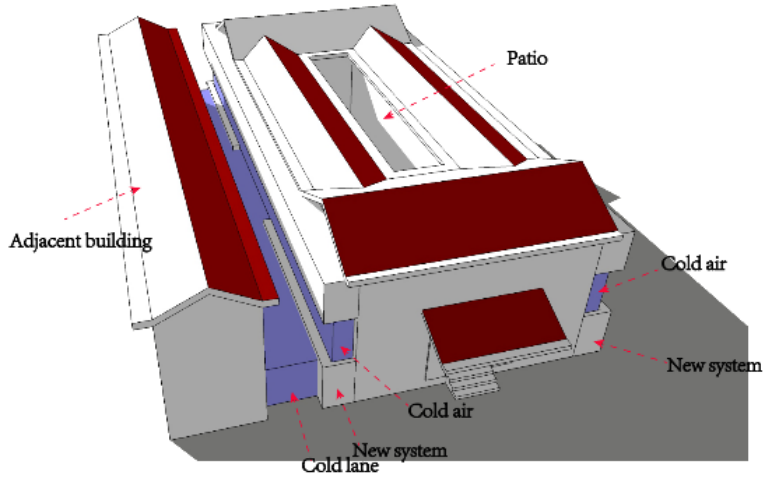

(a) Patio without the glass roof.

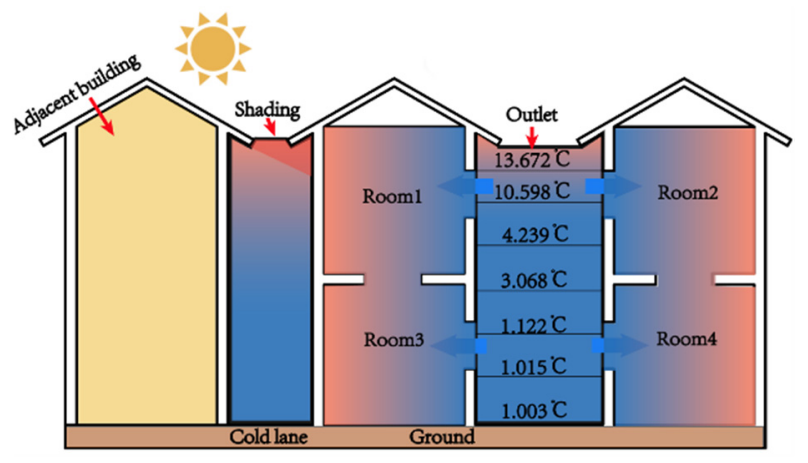

(c) Heat exchange in the courtyard without the glass roof.
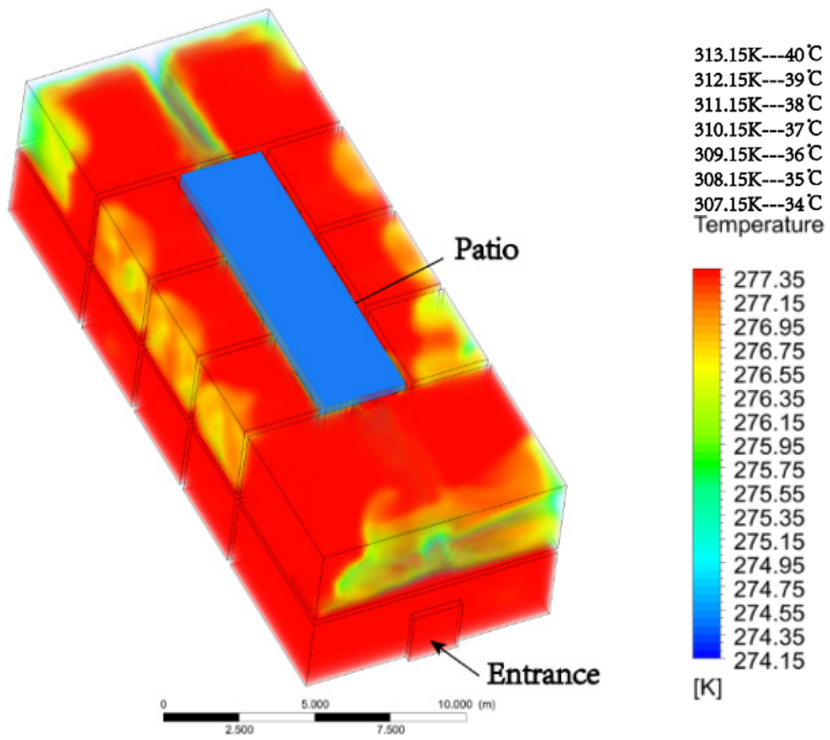

(e) Heat transfer in the courtyard without the glass roof.

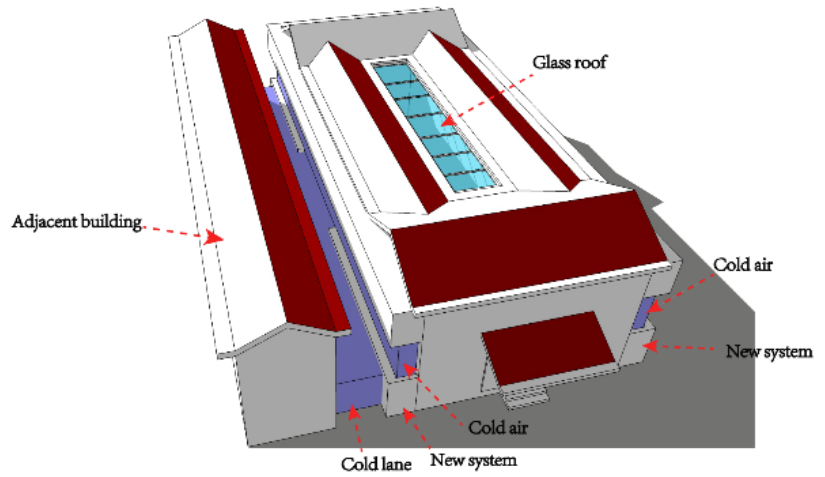

(b) Patio with the glass roof.

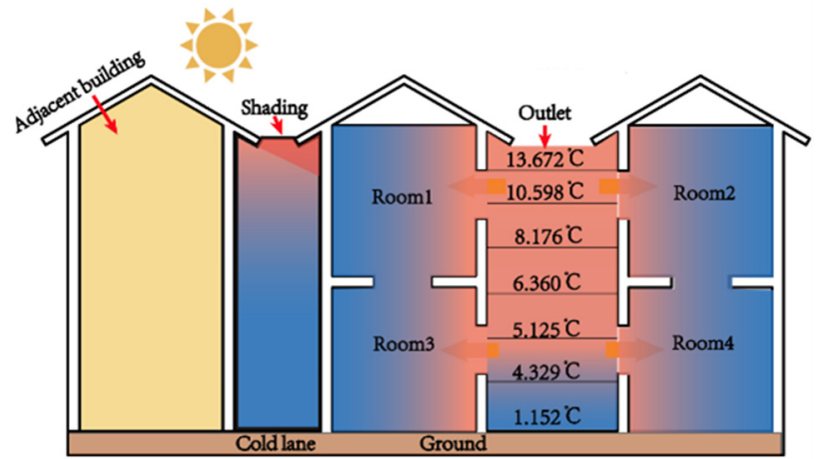

(d) Heat exchange in the courtyard with the glass roof.

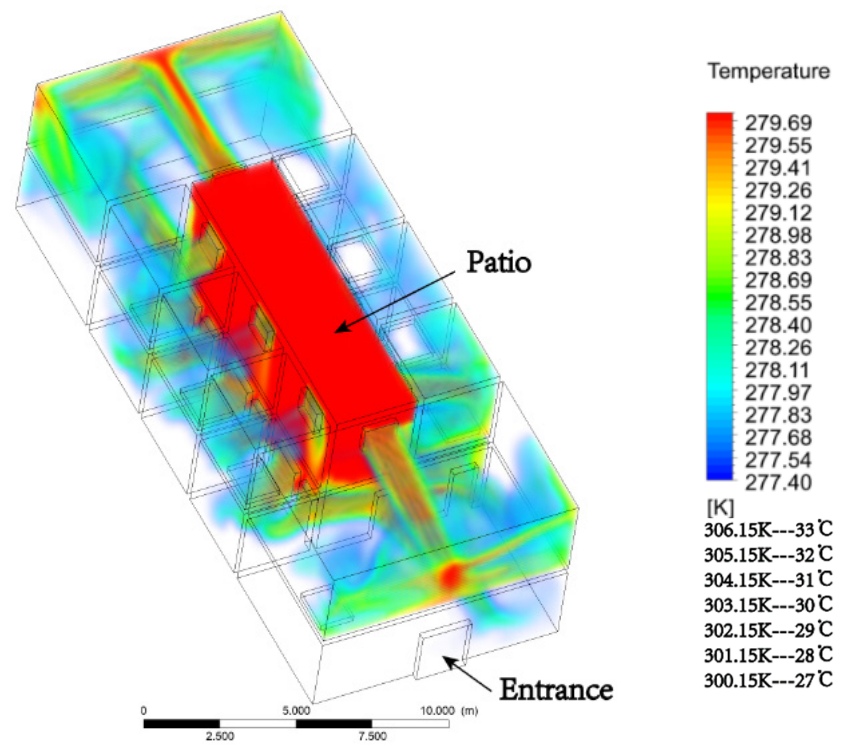

(f) Heat transfer in the courtyard with the glass roof.

Figure 9. Introduction of the glass roof.

\subsection{Simulation Steps and Related Software}

To obtain a clearer understanding of the research process and the reduced cooling load of the new system, the increase in ventilation efficiency, the time the system is suitable for opening, and the number of days in the year in which the indoor comfort increased, software is needed for accurate calculations and expressions. The thermal insulation wall simulation for the new system used the steady-state thermal module in ANSYS, which can very accurately simulate a masonry structure and the heat transfer process of air. The Fluent module in ANSYS was used to simulate the indoor cooling and ventilation using 
cold alleys. The large eddy simulation could accurately calculate the indoor transient ventilation situation, and radiation algorithms were used to calculate the heat conversion process between building interior walls and indoor air, as well as to calculate the heat conversion process between cold air in the cold alleys and indoor hot air. For the solar radiation analysis of the entire village and simulation of the cooling load of the new system, "Ladybug" and "Honeybee" in "Grasshopper" were mainly used. "Rhinoceros" was used to build the building model, "Ladybug" was used to calculate the weather parameters, and "Honeybee" was mainly used to input the related thermal environment parameters and connect to an Energy Plus system.

\subsubsection{Model Building and Grid Setting}

In the geometry module of CFD, the reconstructed building model was built according to the actual scale, and the grid was divided according to the method provided by Arturs S. et al. [50], and the finite element simulation method was used to analyze the distribution of indoor temperature and airflow. The second-order upwind advection scheme was used in the model, which is conducive to the discretization of variables. In order to increase the reliability of the simulated data, it was necessary to establish a convergence criterion for the case study. The convergence standard for energy and temperature is $10^{-6}$ and the convergence standard for other parameters is $10^{-4}$. Reasonable setting of the mesh grid plays a vital role in the accuracy of the solution and will have a huge impact on the simulation time and the degree of convergence. Arturs S. et al. [50] used 0.34, 0.55, $0.98,1.54,1.92$, and 2.09 million hexagonal grids in the simulation during the simulation, and performed local encryption processing in the details of the model. In this study, the division method of the overall division and partial encryption was also adopted. Meshing uses the proximity and curvature of the surface grid to divide the model into 5.409 million units. The number of grids is controlled by changing the maximum and minimum values of the grid and the growth rate of the grid size change. This will significantly speed up the calculation time and can more finely process the details of the interior of the building, thereby making the simulated results more accurate. For the setting of wall layers, it was necessary to ensure that all wall layers were evenly distributed in the model. The uniform wall layer distribution will make the radiation heat transfer more accurate. In this study, five wall layers were set up; the layer coefficient was 0.65 , the level was 1.3 , and the difference between two adjacent grids was kept at about $5 \%$. According to the verification of Arturs S. et al. [50], after considering the configuration of the computer and calculating the deviation of each parameter, it was found that the deviation of the average wind speed was within $2.8 \%$, and the deviation of the temperature was only $0.8 \%$.

\subsubsection{Boundary Condition}

The equation conditions, including the airflow and energy distribution, were established, which were mainly composed of the turbulent kinetic energy $k_{\text {inlet }}$ at the entrance and the energy dissipation rate $\varepsilon_{\text {inlet }}$ :

$$
\begin{gathered}
k_{\text {inlet }}=1.5\left(v_{\text {inlet }} T u\right)^{2} \\
\varepsilon_{\text {inlet }}=\frac{C_{\mu}^{3 / 4} k_{\text {inlet }}^{3 / 2}}{0.07 D_{\text {hinlet }}}
\end{gathered}
$$

\subsubsection{Governing Equation}

Xuelin Z. et al. [51] proposed the flow field setting equation in the calculation domain when using CFD for air flow simulation. The advantages and disadvantages between the Navier-Stokes (RANS) equation and large eddy simulation (LES) are discussed in detail. The paper proposes that the RANS simulation may be computationally more economical, time-saving, and more versatile, but RANS cannot resolve fluctuating flow variables, so turbulence components must be removed from the simulation. In addition, they cannot 
simulate vortex shedding, and they usually overestimate the turbulent kinetic energy near the stagnation point and the flow recirculation of the airflow. LES can solve the governing equations of eddy currents larger than the sub-grid scale and can minimize the abovementioned shortcomings of RANS. Using LES to simulate turbulence can provide more realistic flow data, including flow intermittent and separation in and around buildings, but this requires a lot of additional calculations. In this study, it is necessary to view the flow data during the simulation at any time and calculate the time for the indoor temperature to reach a steady state. In order to make the simulation more accurate, LES was finally selected as the main simulation method.

The flow field in the computational domain was modeled as an instantaneous, threedimensional Navier-Stokes equations for a confined, incompressible viscous flow of a Newtonian fluid using Equations (3)-(5) [52]:

$$
\begin{gathered}
\frac{\partial u_{i}}{\partial x_{i}}=0 \\
\frac{\partial u_{i}}{\partial t}+\frac{\partial}{\partial x_{i}}\left(u_{i} u_{j}\right)=-\frac{1}{\rho} \frac{\partial p}{\partial x_{i}}+\frac{\partial}{\partial x_{j}}\left(2 v s_{i j}\right) \\
\frac{\partial c}{\partial t}+\frac{\partial}{\partial x_{j}}\left(c u_{j}\right)=\frac{\partial}{\partial x_{j}}\left(D \frac{\partial c}{\partial x_{j}}\right)
\end{gathered}
$$

where $u_{i}$ and $x_{i}$ are the instantaneous velocity and position vectors; $p$ is the instantaneous pressure; $t$ denotes time; $\rho$ denotes density; $v$ is the kinematic molecular viscosity; $c$ is the instantaneous concentration; $D$ is the molecular diffusion coefficient or molecular diffusivity; and $s_{i j}$ is the strain-rate tensor as defined in Equation (6):

$$
s_{i j}=\frac{1}{2}\left(\frac{\partial u_{i}}{\partial x_{j}}+\frac{\partial u_{i}}{\partial x_{j}}\right)
$$

\subsubsection{Large Eddy Simulation (LES)}

LES applies a filter function to filter scales smaller than size $\Delta$ from the variables in the Navier-Stokes equations. The rearranged Navier-Stokes equations with the filtered variables, denoted by the tilde, can be expressed as:

$$
\begin{gathered}
\frac{\partial \widetilde{u}_{i}}{\partial \widetilde{x}_{i}}=0 \\
\frac{\partial \widetilde{u}_{i}}{\partial t}+\frac{\partial}{\partial x_{j}}\left(\widetilde{u}_{i} \widetilde{u}_{j}\right)=-\frac{1}{p} \frac{\partial \widetilde{p}}{\partial x_{i}}+\frac{\partial}{\partial x_{j}}\left(2 v \widetilde{s}_{i j}\right)-\frac{\partial \tau_{i j}}{\partial x_{j}} \\
\frac{\partial \widetilde{c}}{\partial t}+\frac{\partial}{\partial x_{j}}\left(\widetilde{c} \widetilde{u}_{j}\right)=\frac{\partial}{\partial x_{j}}\left(D \frac{\partial \widetilde{c}}{\partial x_{j}}\right)-\frac{\partial q_{c, i j}}{\partial x_{j}}
\end{gathered}
$$

where $\widetilde{s}_{i j}$ is the rate of the strain tensor and $\tau_{i j}$ and $q_{c, i j}$ are the subgrid-scale (SGS) Reynolds stresses and the subgrid-scale mass fluxes, respectively. $\tau_{i j}$ is estimated using the WallAdapting Local Eddy-viscosity (WALE) model (Equations (10) and (11)) in this study:

$$
\begin{gathered}
\tau_{i j}-\frac{1}{3} \tau_{k k} \delta_{i j}=-2 \mu_{t} \widetilde{s}_{i j} \\
\mu_{t}=\rho L_{s}^{2} \frac{\left(s_{i j}^{d} s_{i j}^{d}\right)^{3 / 2}}{\left(\bar{s}_{i j} \bar{s}_{i j}\right)^{5 / 2}+\left(s_{i j}^{-d} s_{i j}^{-d}\right)^{5 / 4}}
\end{gathered}
$$


In Equation (10), $\mu_{t}$ is the SGS turbulent viscosity and $\tau_{k k}$ is the isotropic part of the SGS stresses. In Equation (11), $L_{s}$ is the mixing length (Equation (12)) and $s_{i j}$ is the rate of strain (Equation (13)):

$$
\begin{gathered}
L_{s}=\min \left(k d, C_{t o} V_{c e l l}^{1 / 3}\right) \\
s_{i j}^{d}=\frac{1}{2}\left(g_{i j}^{-2}+g_{i j}^{-2}\right)-\frac{1}{3} \delta_{i j} g_{k k}^{-2}, \text { where } \bar{g}_{i j}=\frac{\partial \bar{u}_{i}}{\partial x_{j}}
\end{gathered}
$$

\subsubsection{Calculation of the Radiation and Convection Heat Transfer Coefficient}

According to the research of Mengying Z. et al. [53], the surface to surface (S2S) model is used to calculate the radiative heat transfer. The size in the simulation was the same as the real building. The measured average temperature of each wall was used as the boundary condition. CFD can directly calculate the angle of view coefficient with the wall. The subsequent $h_{r}$ was calculated based on Equation (14), this radiation analysis method has been verified by Yang et al. [54] and used by Gao et al. [55]. Then, $h_{c}$ is calculated by Equation (15).

$$
h_{r}=\frac{q_{r}}{\left(T_{\text {air }}-T_{\text {wall }}\right)}
$$

where $h_{r}\left(\mathrm{~W} /\left(\mathrm{m}^{2} \cdot \mathrm{K}\right)\right)$ is the radiant heat transfer coefficient, $q_{r}\left(\mathrm{~W} / \mathrm{m}^{2}\right)$ is the radiant heat flux, and $T_{\text {air }}(\mathrm{K})$ and $T_{\text {wall }}(\mathrm{K})$ are the surface of the hand and the wall surface temperature, respectively.

$$
h_{c}=\frac{q_{\text {Total }}-q_{r}}{T_{a i r}-T_{a m b}}
$$

where $h_{c}\left(\mathrm{~W} /\left(\mathrm{m}^{2} \cdot \mathrm{K}\right)\right)$ is the convective heat transfer coefficient, $q_{\text {Total }}\left(\mathrm{W} / \mathrm{m}^{2}\right)$ is the heat flux required to keep each area of THM at $308.15 \mathrm{~K}$, and $T_{a m b}(\mathrm{~K})$ is the ambient temperature.

\subsubsection{Surface to Surface (S2S) Heat Radiation Equation}

$\nabla q_{r}$ in the energy equation is the divergence of the radiative heat flux, which was described by the surface to surface (S2S) model:

$$
q_{r, m}=\varepsilon_{m} \sigma T_{m}^{4}-\left(1-\varepsilon_{m}\right) \sum_{n=1}^{N} F_{m, n} q_{r, n}
$$

where $q_{r, m}$ is the energy flux leaving the surface $m, \varepsilon_{m}$ is the emissivity, $\sigma$ is the StefanBoltzmann constant, $q_{r, n}$ is the energy flux leaving the surface $n$, and $F_{m, n}$ is the view factor between surface $n$ and surface $m$, described as follows:

$$
F_{m, n}=\frac{1}{A_{m}} \iint \frac{\cos \theta_{m} \cos \theta_{n}}{\pi r^{2}} \delta_{m n} d A_{m} d A_{n}
$$

where $\delta_{m n}$ is determined by the visibility of $d A_{n}$ to $d_{m} . \delta_{m n}=1$ if $d A_{m}$ is visible to $d A_{n}$ and 0 otherwise.

\subsubsection{Calculation Program}

ANSYS FLUENT uses the finite volume method to solve the governing equations. The COUPLED algorithm is used for pressure-velocity coupling and basing on the least square method for gradient discretization. The body force weighting scheme was used as a spatial discretization method of pressure. Second-order algorithms were used for momentum, turbulence, and energy equations.

\subsubsection{CFD and Energy Plus Co-Simulation Simulation}

According to the method provided by Rui Z. et al. [56], the coupling method between CFD and Energy Plus can be divided into three types: 
- Fully internally coupled, in which the nodal model and CFD model equations are solved iteratively together.

- Iterative external coupling, in which the nodal model and the CFD model equations are solved separately, and the variables are exchanged through an iterative process until the convergence state is reached.

- Progressive replacement external coupling, in which the set of variables is exchanged after each model reaches the state of convergence at each time step.

Rui Z. et al. obtained the benefits of external coupling through systematic research in three aspects: 1 . Lower computational cost; 2 . Nodes and CFD models can be maintained and updated separately; 3 . Configurable exchange variables. This method is the most suitable method for studying building natural ventilation. Therefore, this research will implement a gradual replacement of the external coupling strategy. The exchange variables will be exchanged after each model, node, and CFD model reaches the convergence state at each time step. The simulation steps were mainly divided into five items, and the main analysis method was a comparative analysis. First, the basic case and building energy consumption after the insulation wall was added were simulated and compared to determine the reduction in the cooling load. Second, the passive cooling process of the building using the cold alleys in the new system was simulated with and without WHR, and the results were compared with the base case to obtain the cooling load reduction, thermal equilibrium temperature, and cooling efficiency. Third, after simulating the ventilation performance of the new system, the results were compared with those of the basic case to determine the increase in ventilation efficiency. Fourth, the heating situation of the building in the winter after adding the glass roof to the courtyard was simulated and compared with the basic case to obtain the heating load and heating time of the winter system. Finally, by summarizing all of the results, the reduction in the cooling load in summer and the heating load in winter were calculated. Simultaneously, the time that the system could be used in a year was calculated, along with the amount of time that the comfort level increased after using the system.

\section{Results and Discussion}

In this part of the content, for the air insulation wall, the heat transfer process of the basic case and the new wall in the cold alley system is compared and analyzed. For passive cooling, the heat transfer process in the building is simulated and compared between the base case and building without WHR. Secondly, the with WHR and without WHR scenarios were compared and the room cooling time, cooling efficiency, and thermal equilibrium temperature were calculated. For the ventilation performance of the building, we compared the basic case with the building after the new system was installed and explained the impact of the new system on the building's ventilation. For the glass roof of the patio, we compared the heat storage capacity of the courtyard before and after the renovation and the process of indoor heat transfer.

\subsection{Comparison of the Air Insulation Wall and the Basic Case}

During the temperature test of the case study, it was found that the external surface of the building receives long-term direct solar radiation in summer, which causes the external surface temperature to be much higher than the normal outdoor temperature. After measuring the indoor wall temperature and indoor room temperature, the wall temperature was found to be positively correlated with the indoor temperature and indoor wall temperature. As shown in Figure 10, the three temperatures of the building have a parabolic distribution. During the day, between 0:00 and 8:00, the temperature of the outer surface of the building was lower than the indoor temperature, but with the increase in solar radiation, the temperature of the outer surface rose rapidly, exceeding the two indoor temperatures at 8:00. At 15:00, the external surface temperature of the building reached a parabolic peak at a temperature of $67.1^{\circ} \mathrm{C}$. It took a certain amount of time for heat to transfer from the outer surface to the room, so the temperature of the indoor wall 
reached its peak at $16: 00$, at $37.8^{\circ} \mathrm{C}$. In the same way, the heat transfer between the indoor wall and indoor air also took time. The indoor temperature was not only affected by the wall temperature; the air in the courtyard also transferred heat to the room through the doors and windows. Therefore, under the common influence of the various temperatures, the indoor temperature reached its peak at 18:00, and was $38.63^{\circ} \mathrm{C}$. Therefore, it can be concluded that the indoor wall surface temperature and indoor air temperature change with the outer surface temperature of the building, and the delay time between them was approximately $1 \mathrm{~h}$.

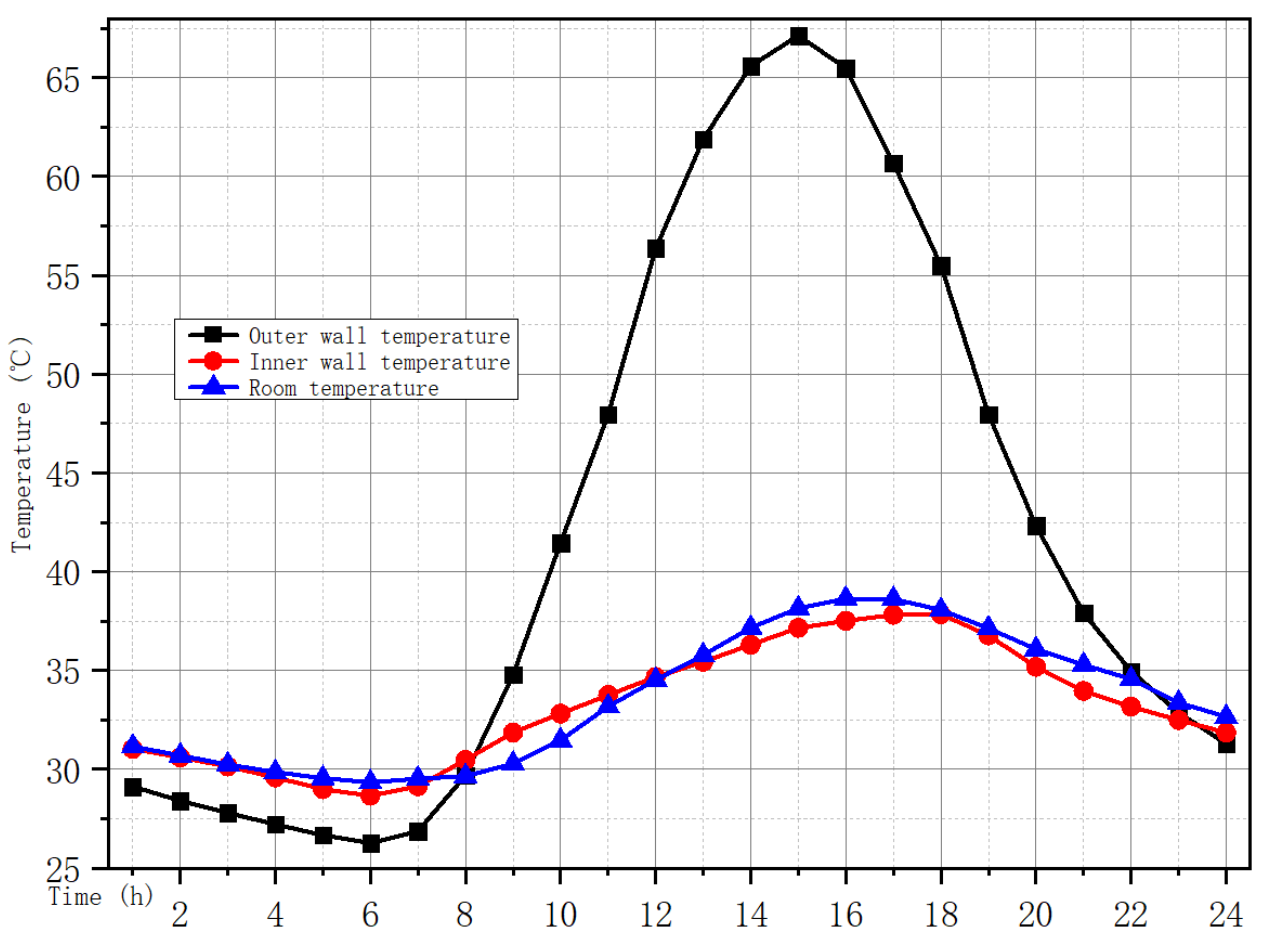

Figure 10. Comparison of the building exterior surface temperature, indoor temperature, and indoor wall temperature.

After the new system was installed in the building, the heat transfer of the wall was simulated and analyzed. Figure 11a shows the original wall heat transfer process for the case study. The outer surface temperature was $67^{\circ} \mathrm{C}$, and the heat reached the room after being transmitted through the wall material. The temperature of the inner wall of the room was $49^{\circ} \mathrm{C}$. This heat continued to exchange heat with the air in the room, causing the indoor temperature to continue to rise. However, as shown in Figure 11b, before the heat from the outer surface entered the room, it was first cooled by the cold air from the cold alley; then, it reached the original wall of the building and finally entered the room. Under the combined influence of the reduced heat consumption through the air wall and passive cooling effect of the new system, the temperature of the inner wall of the room was $37.74{ }^{\circ} \mathrm{C}$. Thus, the temperature dropped by $11.26^{\circ} \mathrm{C}$. Figure $11 \mathrm{c}, \mathrm{d}$ show the heat transfer on the walls and ground of the case study and that of the new system. The building not only transferred heat to the outer surface, the wall near the courtyard was also affected by solar radiation and transferred heat indoors. Between the first and second floors, a heat exchange occurred through the floor. 


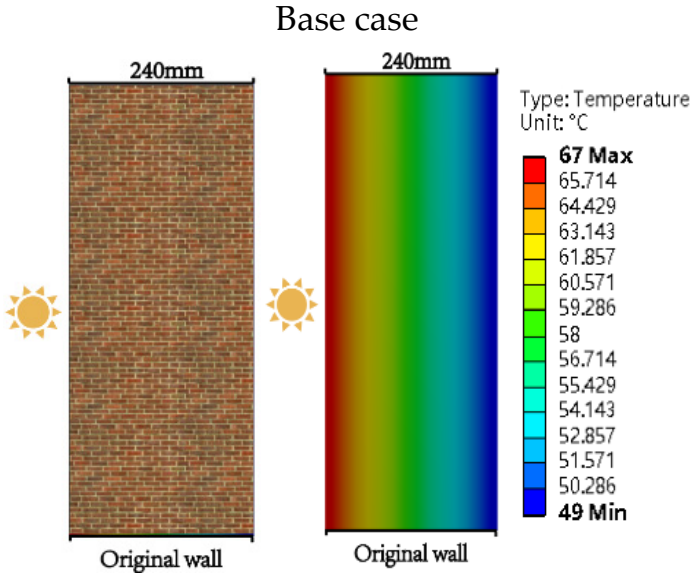

(a) Wall heat transfer analysis of the study case.
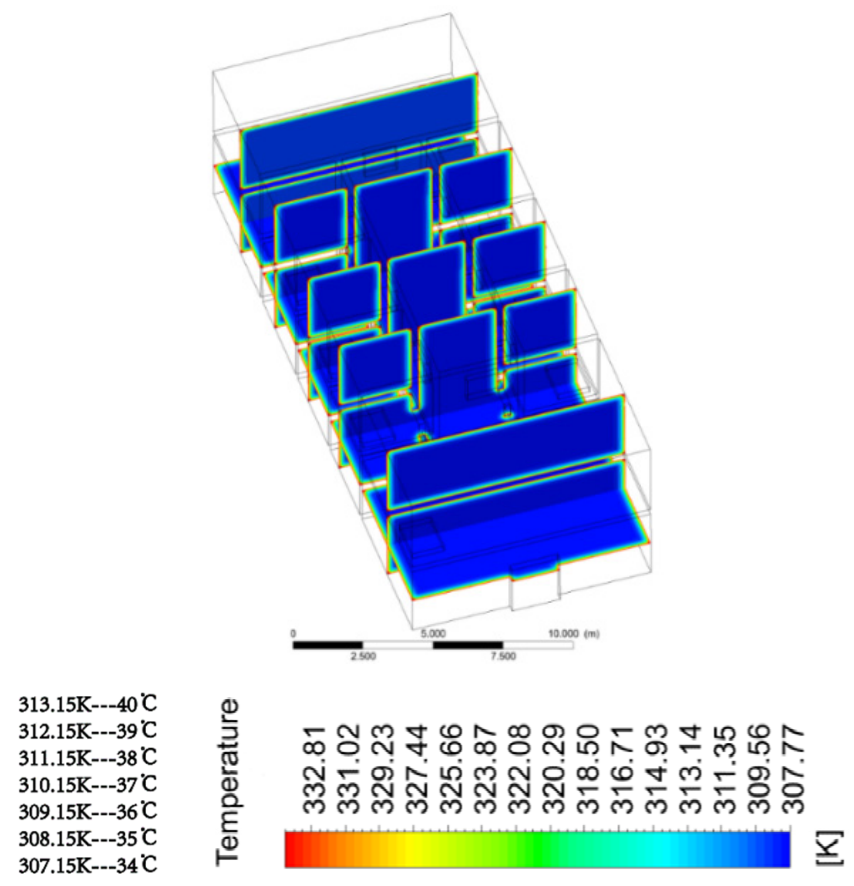

(c) Schematic diagram of the overall wall heat transfer.

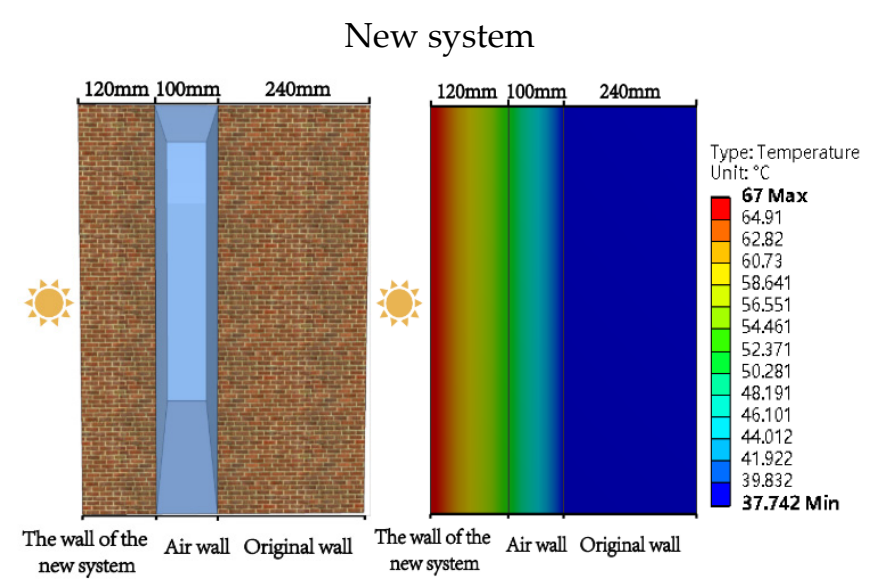

(b) Analysis of the heat transfer of the air insulation wall in the new system.

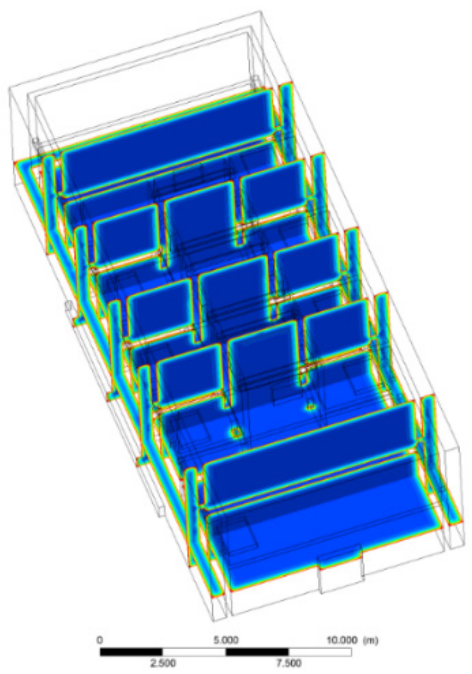

$306.15 \mathrm{~K}---33^{\circ} \mathrm{C}$
$305.15 \mathrm{~K}---32^{\circ} \mathrm{C}$
$304.15 \mathrm{~K}---31^{\circ} \mathrm{C}$
$303.15 \mathrm{~K}---30^{\circ} \mathrm{C}$
$302.15 \mathrm{~K}---29^{\circ} \mathrm{C}$
$301.15 \mathrm{~K}---28^{\circ} \mathrm{C}$
$300.15 \mathrm{~K}---27^{\circ} \mathrm{C}$

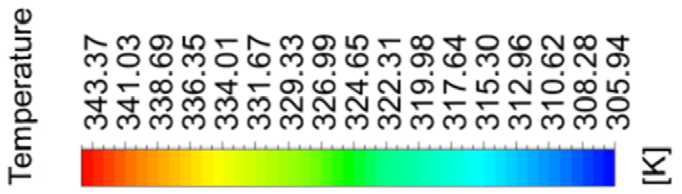

(d) Schematic diagram of the overall wall heat transfer of the new system.

Figure 11. Comparative analysis with and without the air insulation wall.

\subsection{Passive Cooling of the New System and Base Case}

\subsubsection{Comparison of Passive Cooling of the New System with That of the Base Case}

After setting up the new system for the case study, the situation without considering WHR is analyzed in detail. Figure 12 shows the passive cooling process of the base case and that of the new system without the WHR. At $4 \mathrm{~min}$, the base case uses the patio entrance as the main air inlet of the building to transport airflow into the building. In contrast, in the new system, there are two air inlets for the building: the patio entrance and the opening connected to the cold alley. The air temperature at the entrance of the patio was $34^{\circ} \mathrm{C}$, and the air temperature in the cold alley was $28^{\circ} \mathrm{C}$. When the time reached $50 \mathrm{~min}$, it can be seen that in the basic case, the outdoor air entered the building through the courtyard, which initially reduced the courtyard temperature. When the courtyard temperature stabilized, it exchanged heat with each room through the doors and windows. By contrast, at the same time of $50 \mathrm{~min}$, when the passive cooling was conducted based on the cold alley ventilation, 
the cold air in the cold alley avoided the patio and directly introduced cold air into the room, significantly improving the cooling efficiency. Moreover, the second-floor rooms on both sides of the patio are connected by air ducts; therefore, when the temperature of the second-floor room on the side of the cold alley reached the thermal equilibrium point, part of the cold air passed through the stairwell to reach the first floor, and another part of the cold air passed through the air duct entering the opposite room. The air wall surrounding the outside of the building also introduced cold air from the cold alley into the room on the other side; thus, the interactive cooling method can also increase the cooling rate of the room far away from the cold alley. In the ideal state without WHR, all rooms in the base case reached the thermal equilibrium temperature after $6 \mathrm{~h}$. Because the courtyard is used to cool the room, the courtyard temperature is equal to the indoor temperature. The building mainly relies on the normal outdoor temperature for cooling, and the temperature drops by approximately $1{ }^{\circ} \mathrm{C}$. The final room thermal equilibrium temperature was $34^{\circ} \mathrm{C}$, and the cooling rate was $0.166^{\circ} \mathrm{C} / \mathrm{h}$. In contrast, when using the new system for passive cooling, the utilization rate of the cold air was improved, as the heat exchange with the courtyard air was avoided. The entire room reached the thermal equilibrium temperature after $1.66 \mathrm{~h}$. The courtyard and indoor temperatures were quite different. The temperature of the courtyard was $32{ }^{\circ} \mathrm{C}$. The indoor temperature was $28^{\circ} \mathrm{C}$, and the indoor cooling rate was $3.61^{\circ} \mathrm{C} / \mathrm{h}$. However, the temperature of the room near the entrance of the patio was affected by the normal outdoor temperature, and thus, its temperature was higher than that of other rooms, at approximately $33^{\circ} \mathrm{C}$.

$4 \mathrm{~min}$

$313.15 \mathrm{~K}---40 \mathrm{C}$ $312.15 \mathrm{~K}---39^{\circ} \mathrm{C}$ $311.15 \mathrm{~K}---38^{\circ} \mathrm{C}$ $310.15 \mathrm{~K}---37 \mathrm{C}$ $309.15 \mathrm{~K}---36^{\circ} \mathrm{C}$ $308.15 \mathrm{~K}-35^{\circ} \mathrm{C}$ $307.15 \mathrm{~K}---34 \mathrm{C}$
Base case

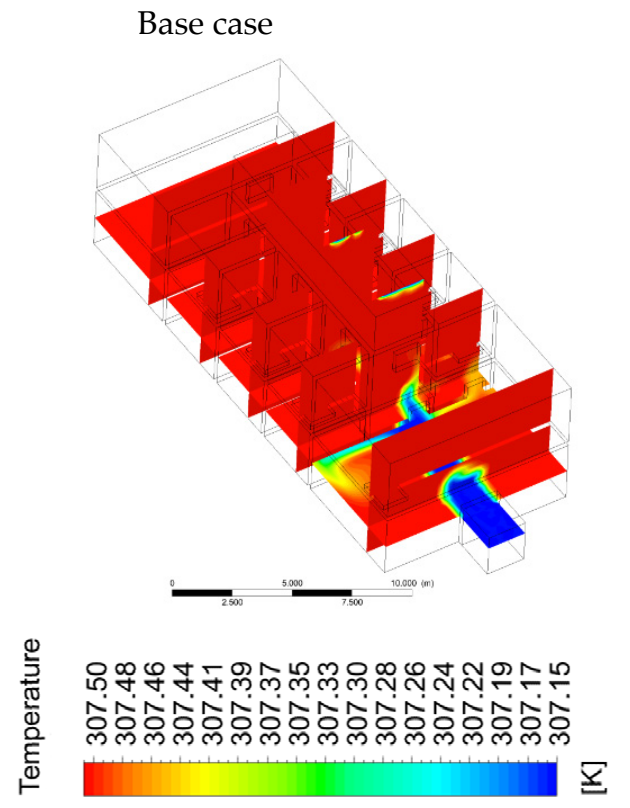

造

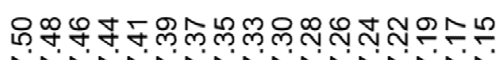

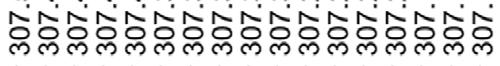

$306.15 \mathrm{~K}---33 \mathrm{C}$

$305.15 \mathrm{~K}---32 \mathrm{C}$

$304.15 \mathrm{~K}---31 \mathrm{C}$

$303.15 \mathrm{~K}---30 \mathrm{C}$

$302.15 \mathrm{~K}---29 \mathrm{C}^{\circ}$

$301.15 \mathrm{~K}---288^{\circ} \mathrm{C}$
$300.15 \mathrm{~K}---27^{\circ} \mathrm{C}$ new system (without WHR)

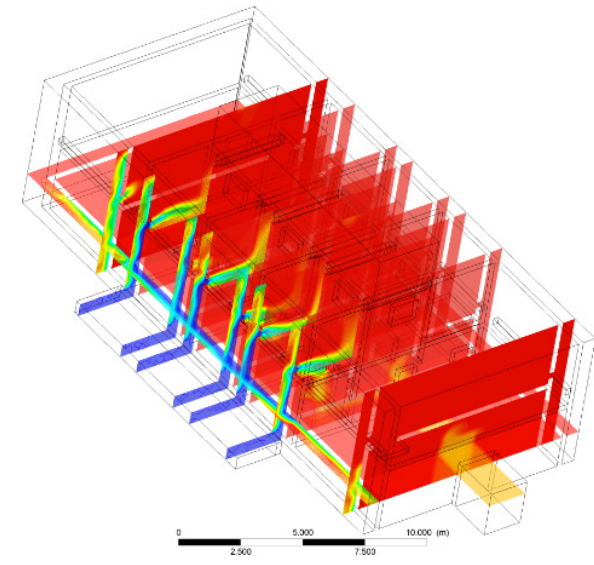

造

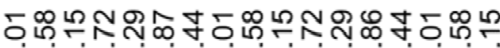

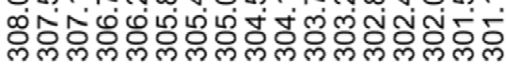

Figure 12. Cont. 
$50 \mathrm{~min}$

$313.15 \mathrm{~K}---40^{\circ} \mathrm{C}$ $312.15 \mathrm{~K}---39^{\circ} \mathrm{C}$ $311.15 \mathrm{~K}---38^{\circ} \mathrm{C}$ $310.15 \mathrm{~K}---37^{\mathrm{C}} \mathrm{C}$ $309.15 \mathrm{~K}---36 \mathrm{C}$ $308.15 \mathrm{~K}---35^{\circ} \mathrm{C}$ $307.15 \mathrm{~K}---34 \mathrm{C}$

$6 \mathrm{~h}$
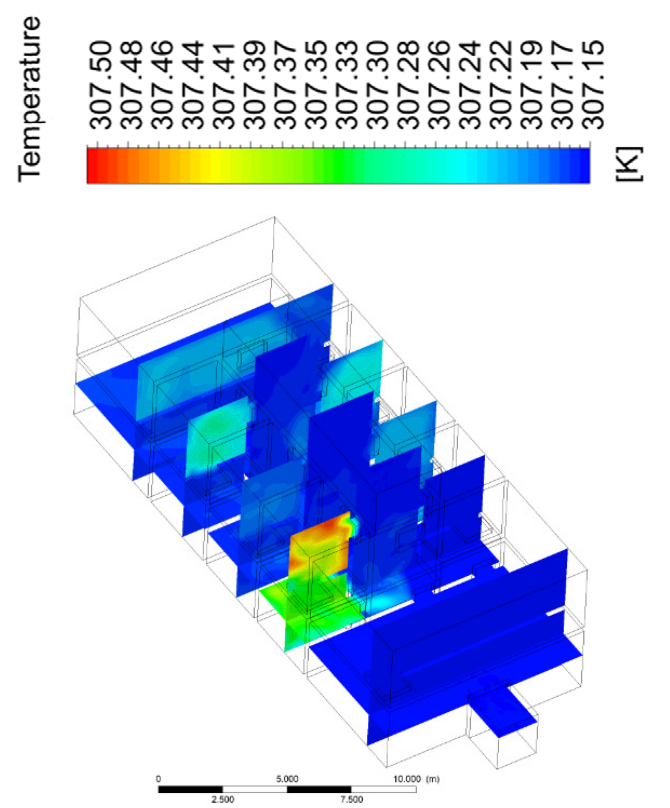

$313.15 \mathrm{~K}---40^{\circ} \mathrm{C}$ $312.15 \mathrm{~K}---39^{\circ} \mathrm{C}$ $311.15 \mathrm{~K}---38^{\circ} \mathrm{C}$ $310.15 \mathrm{~K}---37^{\circ} \mathrm{C}$ $309.15 \mathrm{~K}---36^{\circ} \mathrm{C}$ $308.15 \mathrm{~K}---35^{\circ} \mathrm{C}$ $307.15 \mathrm{~K}---34 \mathrm{C}$

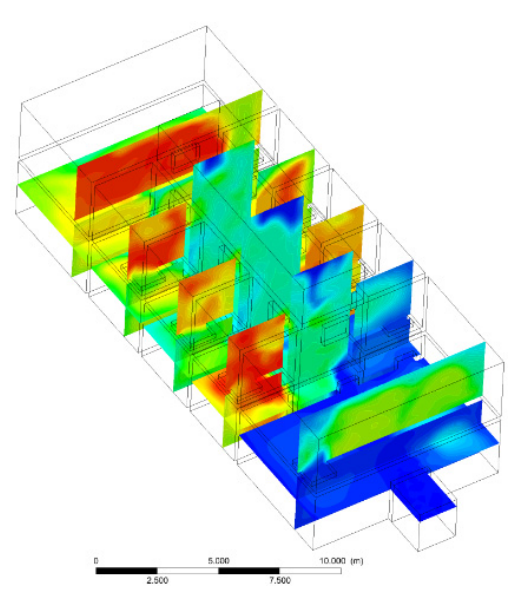

$50 \mathrm{~min}$

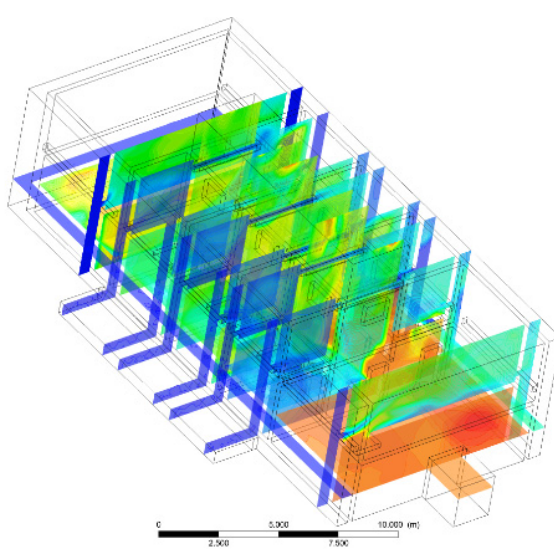

$306.15 \mathrm{~K}---33^{\circ} \mathrm{C}$ $305.15 \mathrm{~K}---32 \mathrm{C}$ $304.15 \mathrm{~K}---31 \mathrm{C}$ $303.15 \mathrm{~K}---30 \mathrm{C}$ $302.15 \mathrm{~K}---29 \mathrm{C}$ $301.15 \mathrm{~K}---28 \mathrm{C}$

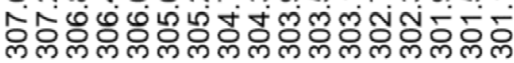

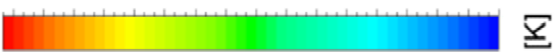

$1.66 \mathrm{~h}$

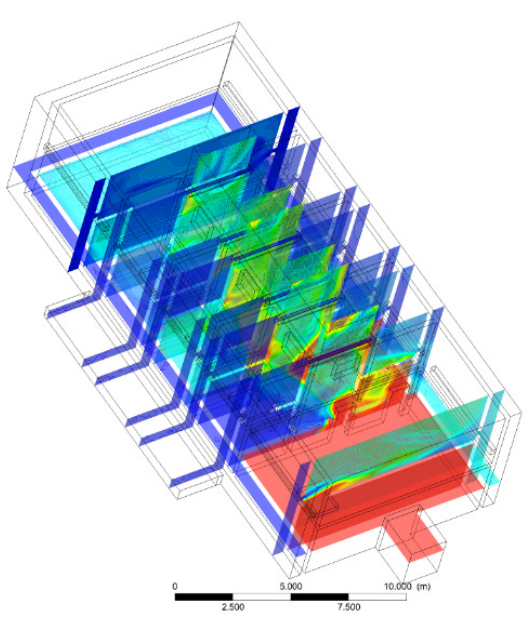

$306.15 \mathrm{~K}---33^{\circ} \mathrm{C}$ $305.15 \mathrm{~K}---32 \mathrm{C}$ $304.15 \mathrm{~K}---31 \mathrm{C}$ $303.15 \mathrm{~K}---30^{\circ} \mathrm{C}$ $302.15 \mathrm{~K}---29 \mathrm{C}$ $300.15 \mathrm{~K}---27 \mathrm{C}$

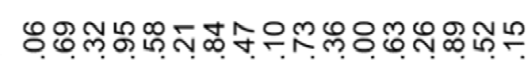

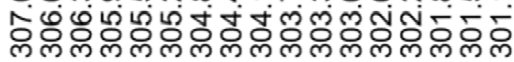

Figure 12. Comparison of passive cooling of the new system with the base case (without WHR).

3.2.2. Cooling Time and Thermal Equilibrium Temperature of the New System with and without WHR

When considering the WHR, the cooling time of the new system and temperature of the heat balance point were affected to a certain extent. As shown in Figure 13, during the first $4 \mathrm{~min}$, the heat transfer conditions with and without WHR were roughly the same. However, when the air in the cold alley entered in the new system, part of the air was affected by the solar radiation and was heated by the envelope structure. At $50 \mathrm{~min}$, the air in both rooms on the side of the cold alley reached the thermal equilibrium temperature and began to flow to the first floor and the room on the side away from the cold alley; the thermal equilibrium temperature changed. In the absence of WHR, the thermal equilibrium temperature of the room near the cold alley was approximately $30^{\circ} \mathrm{C}$, whereas the temperature of the room with WHR was approximately $32^{\circ} \mathrm{C}$. The new system was also affected by the solar radiation. As cold air flowed into the room far from the cold alley, the air storage space in the wall was heated. Therefore, the purpose of cooling the far room could not be achieved within a certain period of time. At this time, the air ducts connecting 
the rooms on both sides played an important role. They directly introduced cold air into the room on one side of the cold alley and into the room on the other side, reducing the cooling time and improving the cooling efficiency. All of the rooms without the influence of WHR reached the thermal equilibrium point after $1.66 \mathrm{~h}$. The average indoor temperature was $28^{\circ} \mathrm{C}$, and the cooling efficiency was $3.61^{\circ} \mathrm{C} / \mathrm{h}$. In the case with WHR, the temperature of all rooms reached the equilibrium point after $1.94 \mathrm{~h}$. The temperature was $32^{\circ} \mathrm{C}$, and the cooling efficiency was $1.03^{\circ} \mathrm{C} / \mathrm{h}$. Although the cooling efficiency of the new system was reduced when considering the WHR of the wall, it was still closer to reality. Nevertheless, this shows that, in the indoor heat transfer simulation, the influence of the WHR on the indoor temperature cannot be ignored.

new system (without WHR)

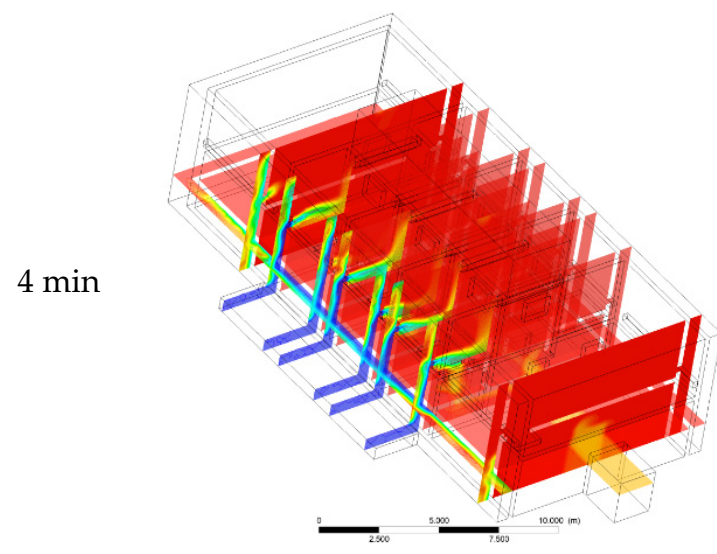

$313.15 \mathrm{~K}---40^{\circ} \mathrm{C}$ $312.15 \mathrm{~K}---39^{\circ} \mathrm{C}$ $311.15 \mathrm{~K}---38^{\circ} \mathrm{C}$ $310.15 \mathrm{~K}---37 \mathrm{C}$ $309.15 \mathrm{~K}---36^{\circ} \mathrm{C}$ $308.15 \mathrm{~K}---35 \mathrm{C}$ $307.15 \mathrm{~K}---34^{\circ} \mathrm{C}$

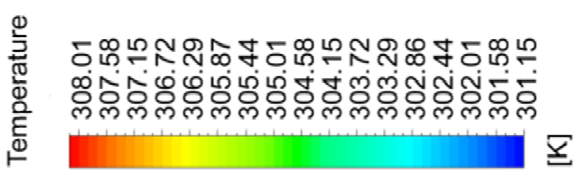

$50 \mathrm{~min}$

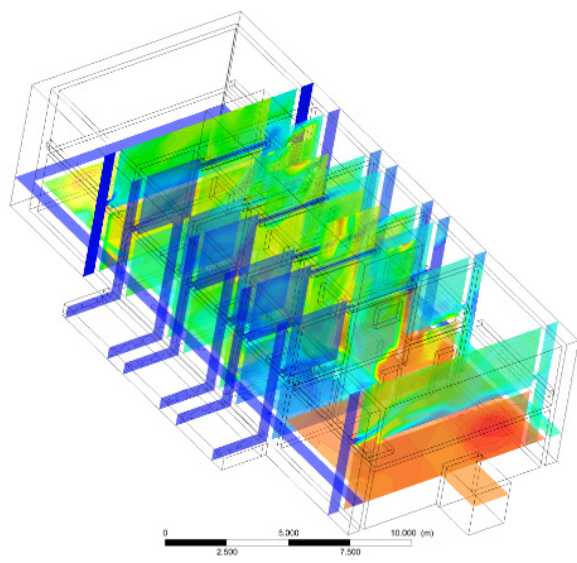
$312.15 \mathrm{~K}---39^{\circ} \mathrm{C}$ $311.15 \mathrm{~K}---38^{\circ} \mathrm{C}$ $310.15 \mathrm{~K}---37 \mathrm{C}$ $309.15 \mathrm{~K}---36 \mathrm{C}$ $308.15 \mathrm{~K}---35^{\circ} \mathrm{C}$ $307.15 \mathrm{~K}---34 \mathrm{C}$
$306.15 \mathrm{~K}---33 \mathrm{C}$ $305.15 \mathrm{~K}---32 \mathrm{C}$ $304.15 \mathrm{~K}---31 \mathrm{C}$ $303.15 \mathrm{~K}---30^{\circ} \mathrm{C}$ $302.15 \mathrm{~K}---29^{\circ} \mathrm{C}$ $301.15 \mathrm{~K}---28{ }^{\circ} \mathrm{C}$ $300.15 \mathrm{~K}---27 \mathrm{C}$

$50 \mathrm{~min}$

new system (with WHR)

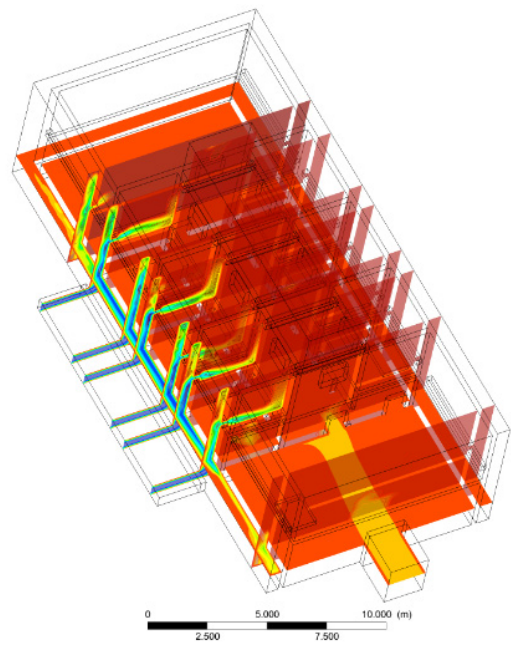

造

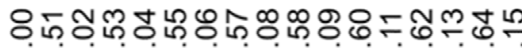
行

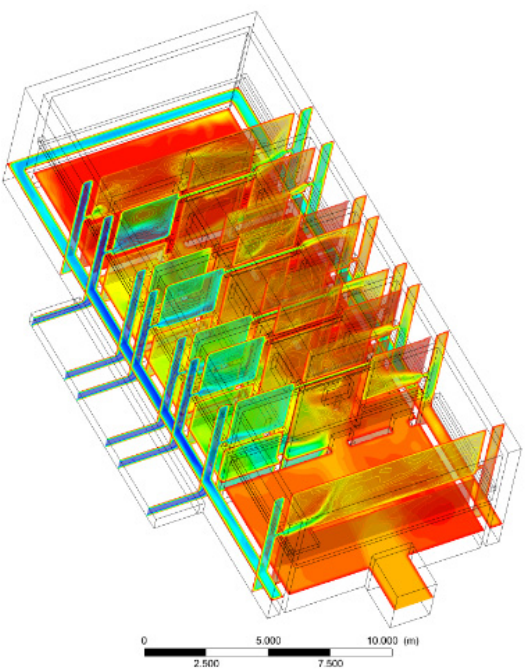

$306.15 \mathrm{~K}---33 \mathrm{C}$ $305.15 \mathrm{~K}---32 \mathrm{C}$ $304.15 \mathrm{~K}---31 \mathrm{C}$ $303.15 \mathrm{~K}---30 \mathrm{C}$ $302.15 \mathrm{~K}---29 \mathrm{C}$ $\underset{ }{\simeq \quad 301.15 \mathrm{~K}---28 \mathrm{C}}$

Figure 13. Cont. 
$1.66 \mathrm{~h}$

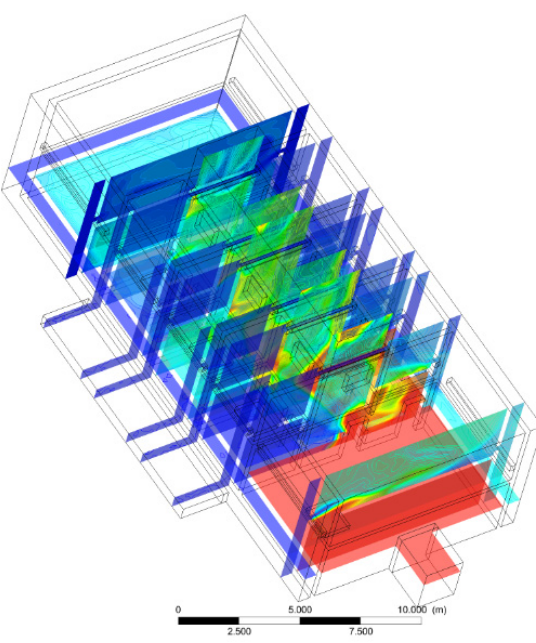

$313.15 \mathrm{~K}---40 \mathrm{C}$ $312.15 \mathrm{~K}---39^{\circ} \mathrm{C}$ $311.15 \mathrm{~K}---38 \mathrm{C}$ $310.15 \mathrm{~K}---37 \mathrm{C}$ $309.15 \mathrm{~K}---36 \mathrm{C}$ $308.15 \mathrm{~K}---35^{\circ} \mathrm{C}$ $307.15 \mathrm{~K}---34 \mathrm{C}$

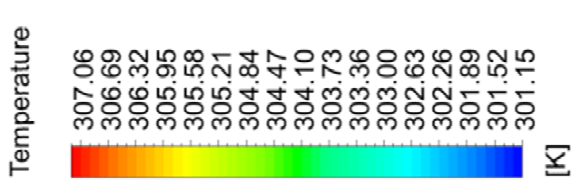

$1.94 \mathrm{~h}$

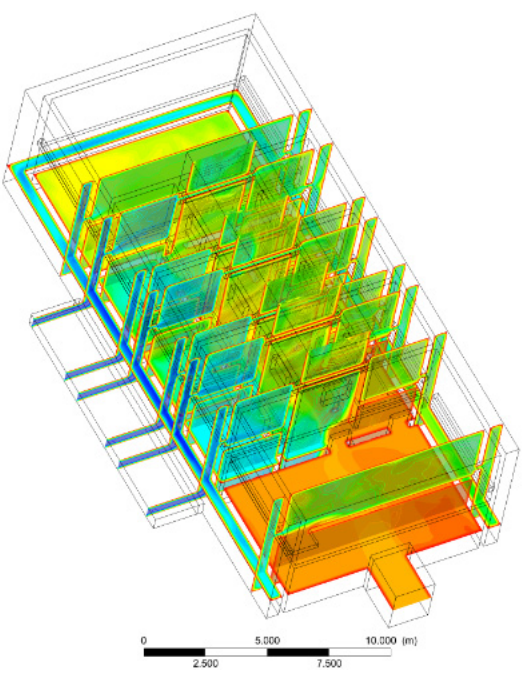

$306.15 \mathrm{~K}---33^{\circ} \mathrm{C}$ $305.15 \mathrm{~K}---32 \mathrm{C}$ $304.15 \mathrm{~K}---31 \mathrm{C}$ $303.15 \mathrm{~K}--30 \mathrm{C}$ $302.15 \mathrm{~K}---29 \mathrm{C}$ $301.15 \mathrm{~K}---28 \mathrm{C}$
选

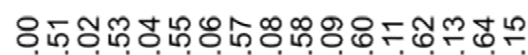

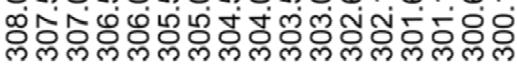

Figure 13. Cooling time and thermal equilibrium temperature of the new system with and without WHR.

\subsection{Comparison of the Natural Ventilation of the New System and the Base Case}

Figure 14 shows a comparison between the ventilation efficiencies of the new system and the base case. It can be seen that within $4 \mathrm{~min}-2.22 \mathrm{~h}$, the air flow in the base case room was slow, and the effect of the ventilation through the patio was not ideal. For the new system, during the period of $4 \mathrm{~min}-1.38 \mathrm{~h}$, the air passed through the cold alley, the top of the patio, and the patio entrance for ventilation. In the courtyard, the air flow in the room was intense and the frequency of air exchange was high. An ideal ventilation effect was achieved within $4 \mathrm{~min}$.

Base case

$4 \min$

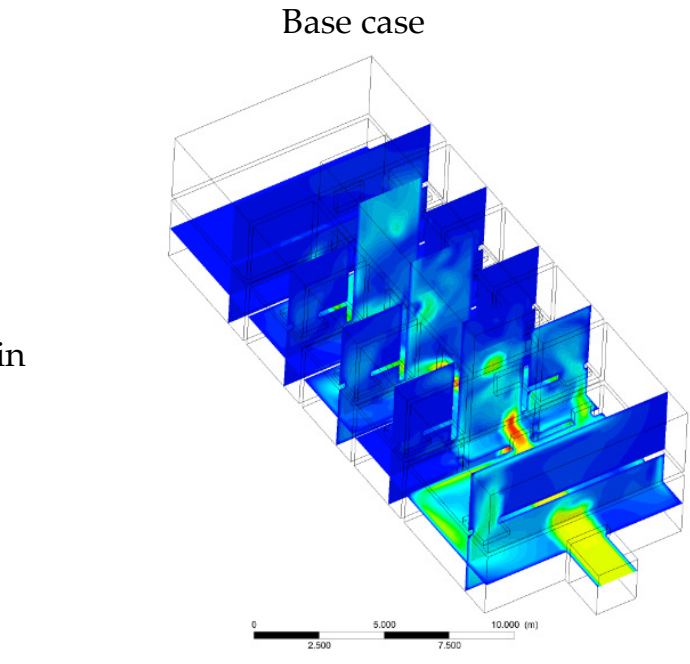

$\frac{7}{3}$

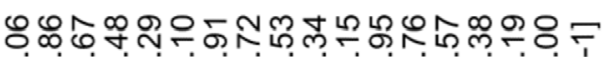
minninin
$4 \mathrm{~min}$

New system
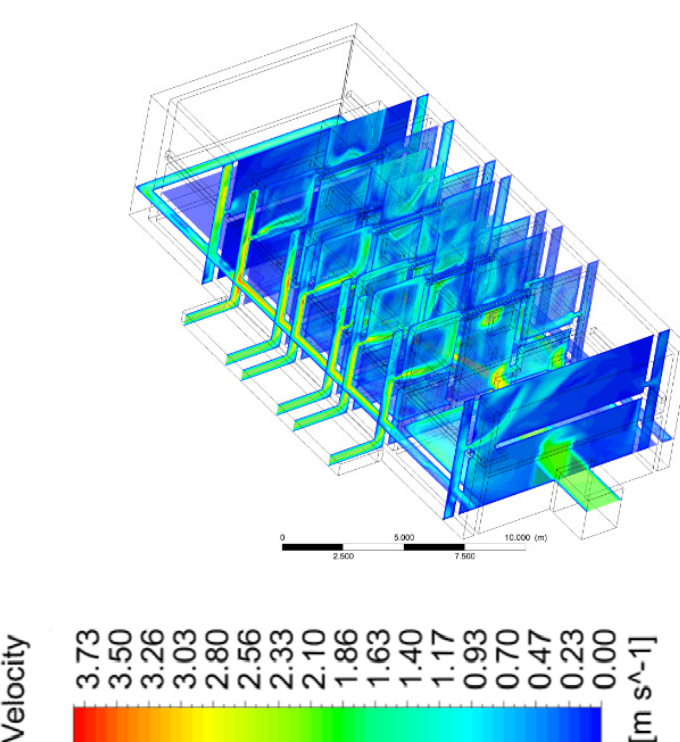

Figure 14. Cont. 
$2.22 \mathrm{~h}$
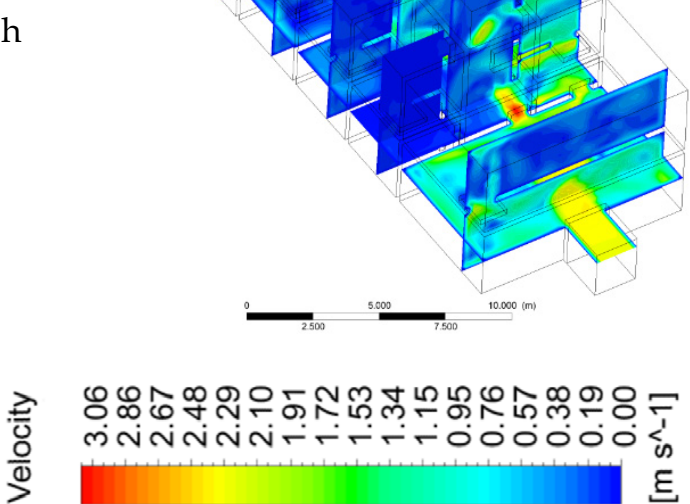

$1.38 \mathrm{~h}$
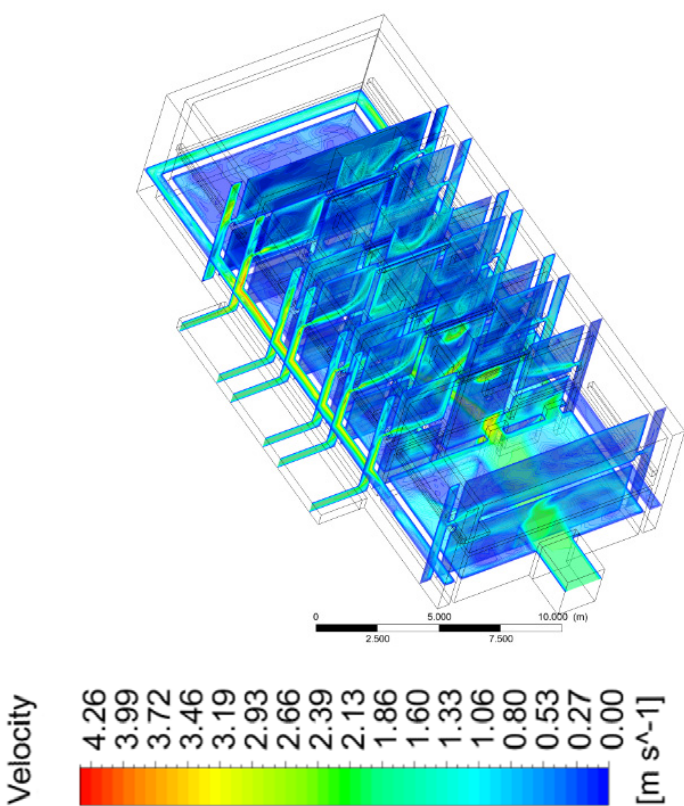

Figure 14. Comparison of the natural ventilation of the new system and the base case.

\subsection{Patio Glass Roof in Winter}

The location in the building that can receive the maximum solar radiation per day is the roof. As shown in Figure 15, after measuring the roof temperature, indoor temperature, and outdoor temperature during the winter solstice, it was found that the outdoor temperature at night was the lowest, the indoor temperature was the highest, and the roof temperature was somewhere in between. However, as the sun rose, the solar radiation gradually increased, and the temperatures at various locations also gradually increased. The three temperatures were the same at 10:00. Then, the temperature of the roof rose the most, reaching a peak of $19^{\circ} \mathrm{C}$ at 15:00. The second-highest was the indoor temperature, which reached a maximum of $9{ }^{\circ} \mathrm{C}$ at 17:00. With regard to the passive insulation strategy for winter buildings, solar radiation was the largest heat source and avoided any energy consumption. If the solar radiant heat on the roof of the building can be effectively collected, it can be stored and then transmitted into a room through the doors and windows, effectively increasing the indoor temperature. To improve the heat storage capacity of the courtyard in winter, it is necessary to install a glass roof at the top of the patio. Therefore, in this study, the air ducts used to connect the rooms on both sides of the courtyard in summer were used as the supporting members for the glass roof, i.e., to facilitate its construction.

June 21 is the summer solstice, and this day's sunshine time is the longest in the year. Thus, the temperature of the case study was measured on this day. In this research, we tried to treat the patio as a constant-temperature heat source which could store heat within a certain period of time and transfer heat to the room. Figure 16 shows a comparative analysis of the heat storage patio with the glass roof and the basic case. At $4 \mathrm{~min}$, the two patios show different effects. In the basic case, the patio has no heat storage function. After entering the patio, the cold air from the outside flowed downward and passed into the room through the doors and windows. However, the patio with the heat storage function played the opposite role. Its existence helped to increase the indoor temperature. After $28.3 \mathrm{~min}$, the patio without the glass roof gathered a large amount of cold air, which continued to enter the room. At this time, the courtyard temperature dropped from $4.18^{\circ} \mathrm{C}$ to $1{ }^{\circ} \mathrm{C}$. For the patio with a glass roof, the temperature started to increase down from the top of the courtyard, and the heat storage was completed after $33.3 \mathrm{~min}$, and the temperature rose from $4.18{ }^{\circ} \mathrm{C}$ to $6.45^{\circ} \mathrm{C}$. For the entire building, this is equivalent to adding a constant heat source with a temperature of $6.45^{\circ} \mathrm{C}$ for continuously heating the rooms near the patio, thereby reducing the heating load of the building. 


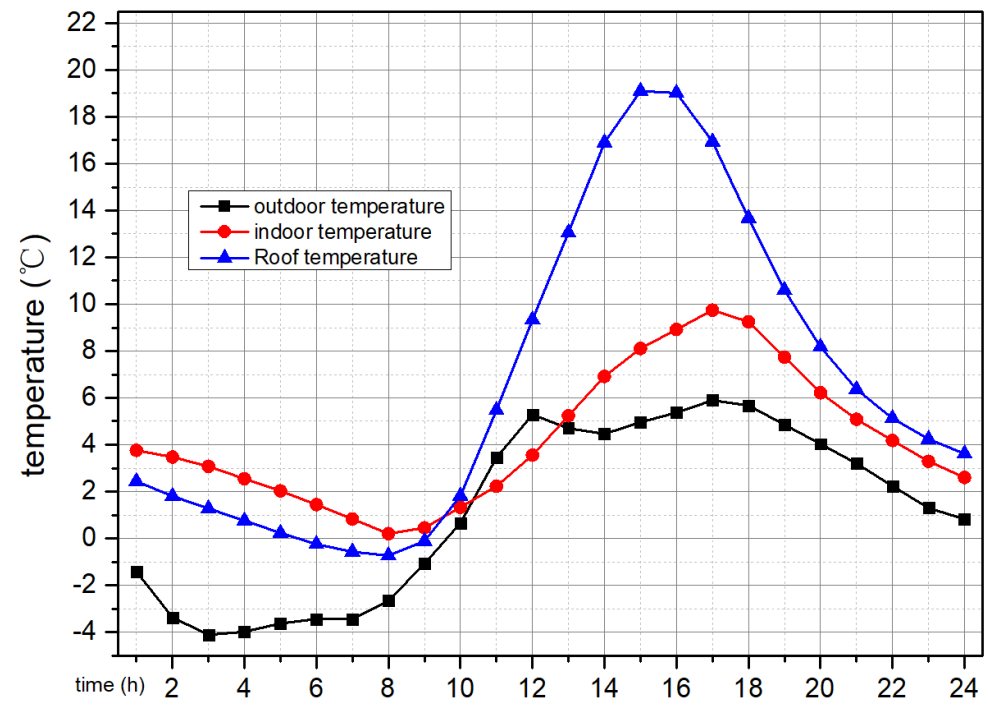

Figure 15. Comparison of the roof temperature, indoor temperature, outdoor temperature.

4 min

$313.15 \mathrm{~K}---40 \mathrm{C}$ $312.15 \mathrm{~K}---39 \mathrm{C}$ $311.15 \mathrm{~K}---388^{\circ} \mathrm{C}$ $310.15 \mathrm{~K}---37^{\circ} \mathrm{C}$ $309.15 \mathrm{~K}---36^{\circ} \mathrm{C}$ $308.15 \mathrm{~K}---35^{\circ} \mathrm{C}$ $307.15 \mathrm{~K}---34 \mathrm{C}$
Base case

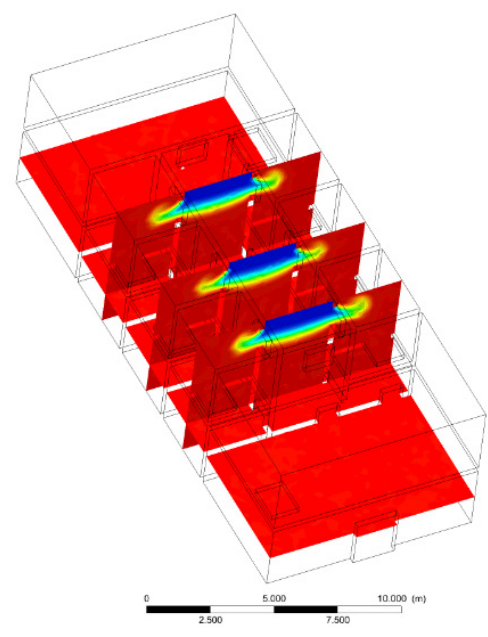

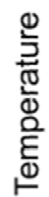

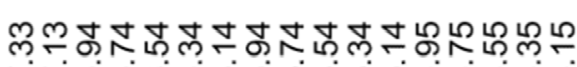

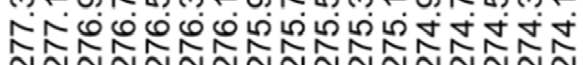

$4 \mathrm{~min}$

Patio with glass roof

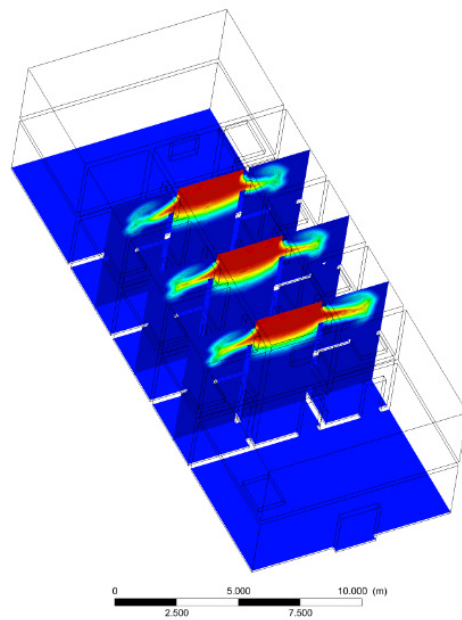

$306.15 \mathrm{~K}---33^{\circ} \mathrm{C}$ $305.15 \mathrm{~K}---32 \mathrm{C}$ $304.15 \mathrm{~K}---31 \mathrm{C}$

$303.15 \mathrm{~K}---30^{\circ} \mathrm{C}$

$302.15 \mathrm{~K}---29^{\circ} \mathrm{C}$

$301.15 \mathrm{~K}---28 \mathrm{C}$

$300.15 \mathrm{~K}---27 \mathrm{C}$
造

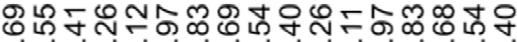

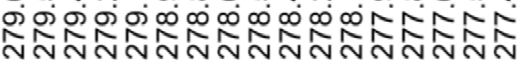

Figure 16. Cont. 
$28.3 \mathrm{~min}$

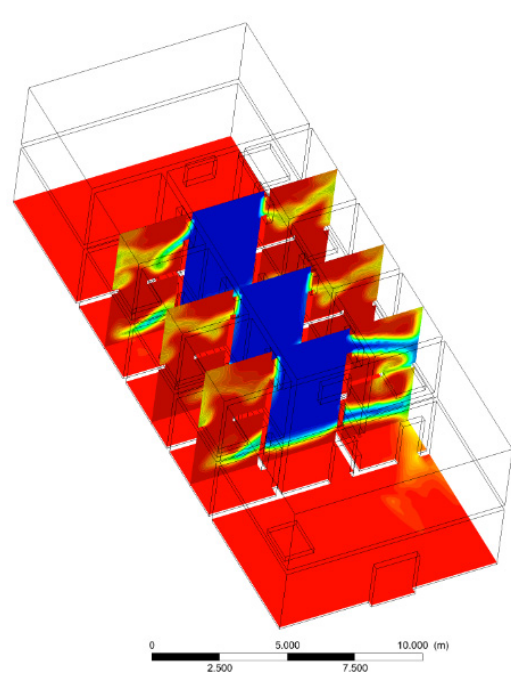

Figure 16. Comparison of the heat transfer with and without the glass roof patio in winter.

With reference to the above analysis and simulation, the load of each part of the new system and the thermal comfort time of the building will be calculated next, and they will be compared with the base case. By comparing the effects before and after adding thermal insulation walls in traditional residential buildings, we estimated the annual cooling load reduction from using thermal insulation walls in summer. The cooling effects of a base case and of a building using the passive system were examined without considering the WHR, aiming to calculate the cooling efficiency inside the building, thermal equilibrium temperature, and reduction of the cooling load for the entire building throughout the year. The cooling effects of the new system with and without WHR were compared, in addition to the room cooling rate, thermal equilibrium temperature, and annual cooling load reduction for the entire building. Based on comparing the heating effects of a courtyard with or without a glass roof in winter, we estimated the time required for a patio to meet the required heating conditions and reduce the total heating load throughout the year. The appropriate utilization time for the new passive system over a year was calculated. According to a local comfort temperature standard, the annual time required to meet the comfort temperature requirement for the base case was estimated, and the annual times required to meet the comfort temperature standard after using the new system with and without WHR were compared.

\subsection{Cooling Load Reduction by the Air Insulation Wall}

Figure 17 shows a comparison of the cooling load of the building with and without an insulating wall during the year. It can be seen from the figure that the cooling load reduction of the building without the insulating wall for the entire year was $56551.03 \mathrm{kWh}$. When the air insulation wall was installed, the reduced cooling load was $55417.33 \mathrm{kWh}$. The difference between them was the cooling load reduction of the air insulation wall, i.e., $1133.7 \mathrm{kWh}$. 


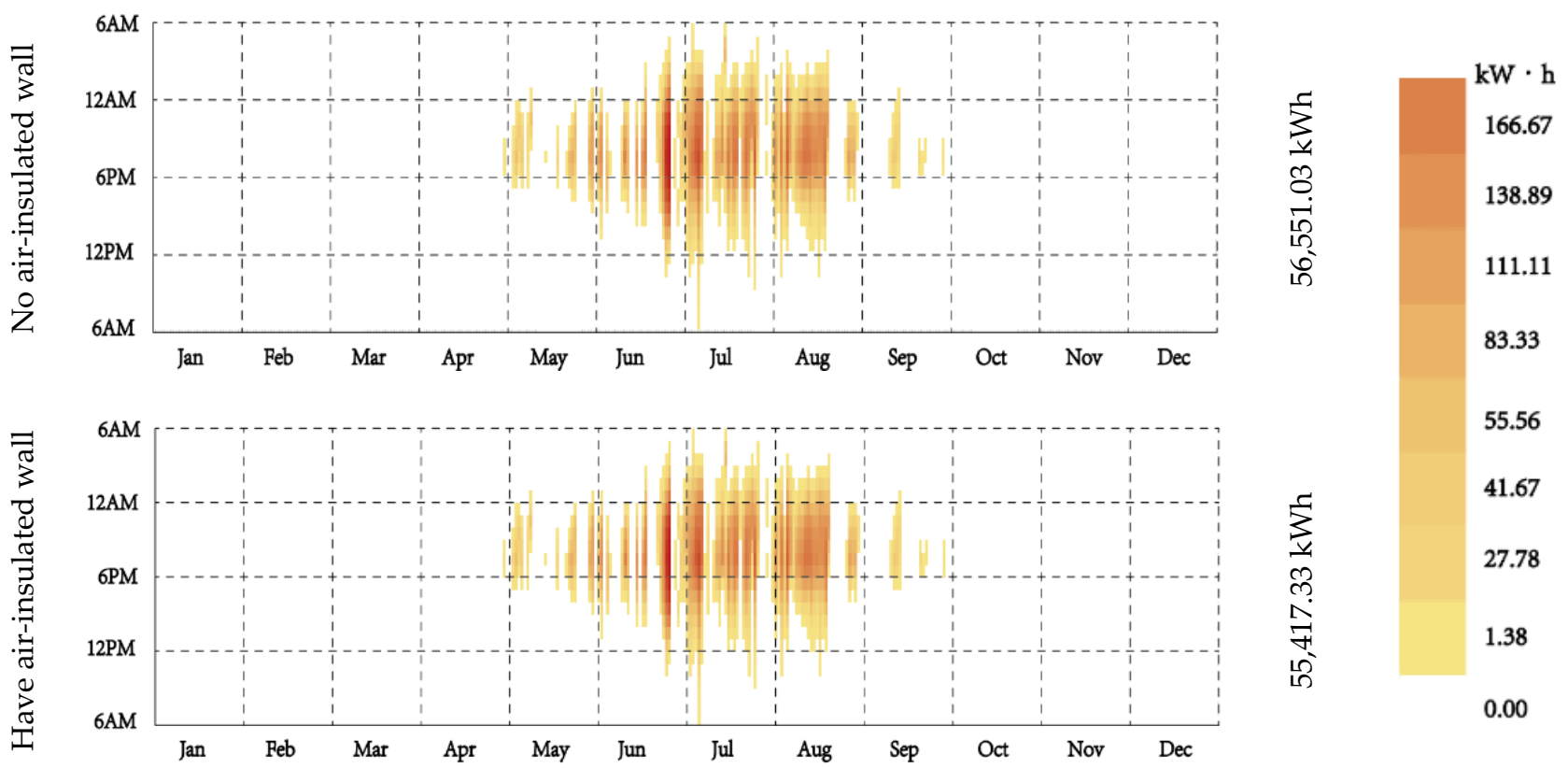

Figure 17. Comparison of the cooling load with and without the air insulation wall.

3.6. Comparison of Whether the New System with WHR Reduces the Cooling Load in Summer

Figure 18 shows the reduction in the cooling load of the building during the year with and without WHR. Without WHR, the cooling load reduction of the entire building was $55,417.33 \mathrm{kWh}$. With WHR, the cooling load reduction was 28,537.57 $\mathrm{kWh}$. The difference between the two was $26,879.76 \mathrm{kWh}$.

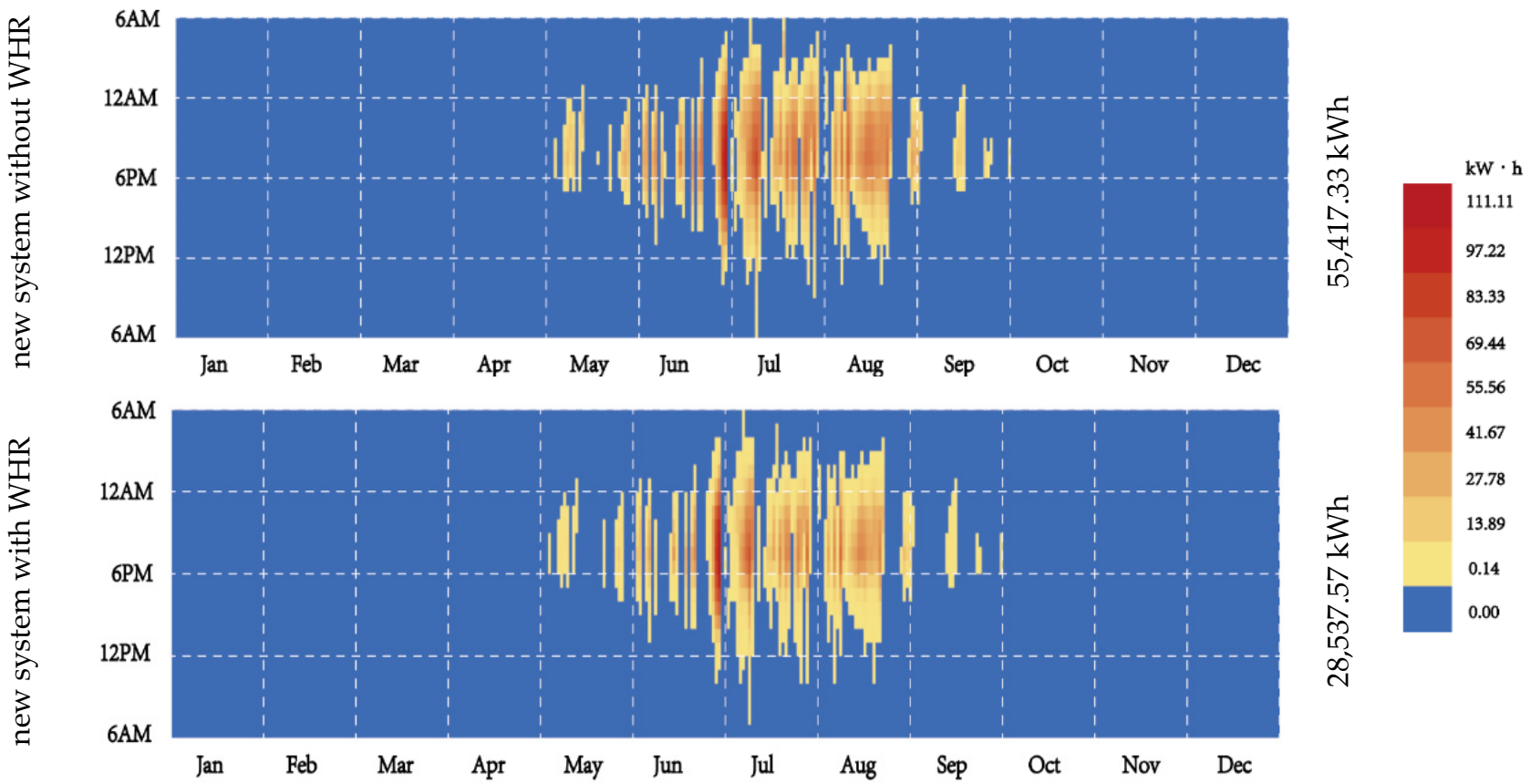

Figure 18. Reduction in the cooling load of the building during the year with and without WHR.

\subsection{Patio Glass Roof Reduces the Heating Load in Winter}

Figure 19 shows that the winter heating load, as reduced by using the glass roof to increase the heat storage capacity of the patio in winter, was $54,537.78 \mathrm{kWh}$. 


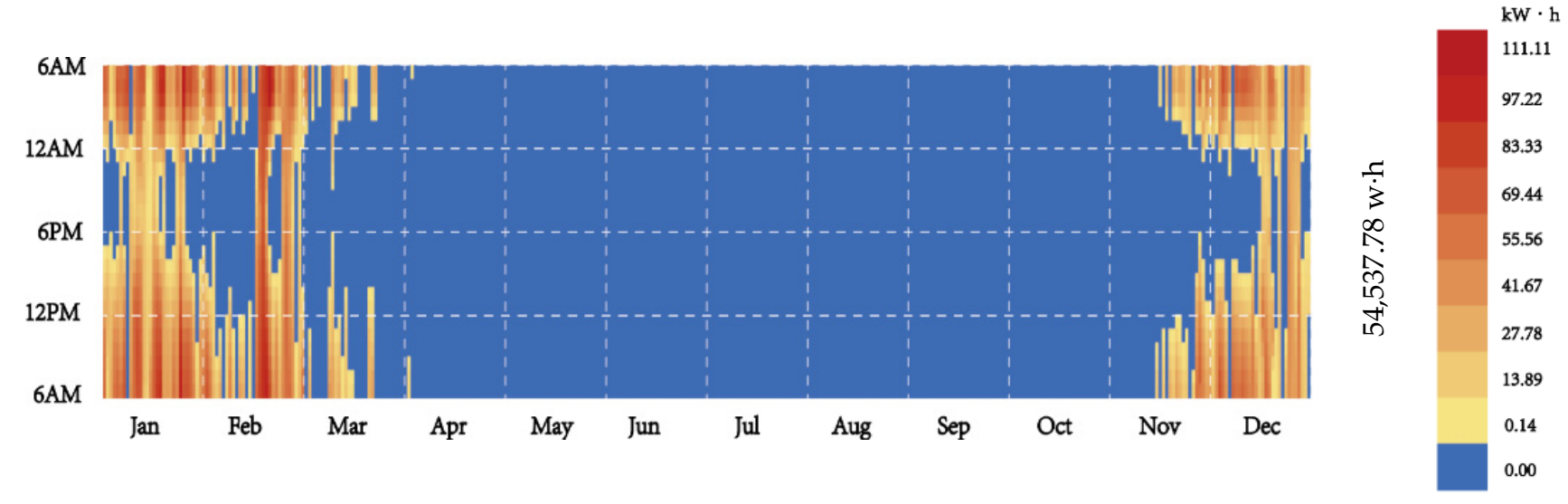

Figure 19. Reduced heating load from the glass roof.

\subsection{Suitable Time for the New System throughout the Year}

The indoor temperature in summer was higher than $28^{\circ} \mathrm{C}$, and the temperature in winter was lower than $6.45^{\circ} \mathrm{C}$; these were used as reference standards for calculating the available time for the new system throughout the year. Figure 20 shows the times when the new system was suitable for use within a year, both with WHR and without WHR, as benchmarks for comparison. It can be seen that with WHR, the suitable time for the new system to be open throughout the year was $2722 \mathrm{~h}$, accounting for $31.07 \%$ of the total time of the year. Without WHR, the suitable time for the new system to be open throughout the year was $2666 \mathrm{~h}$, accounting for $30.43 \%$ of the total annual time. The difference between the two was $56 \mathrm{~h}$.

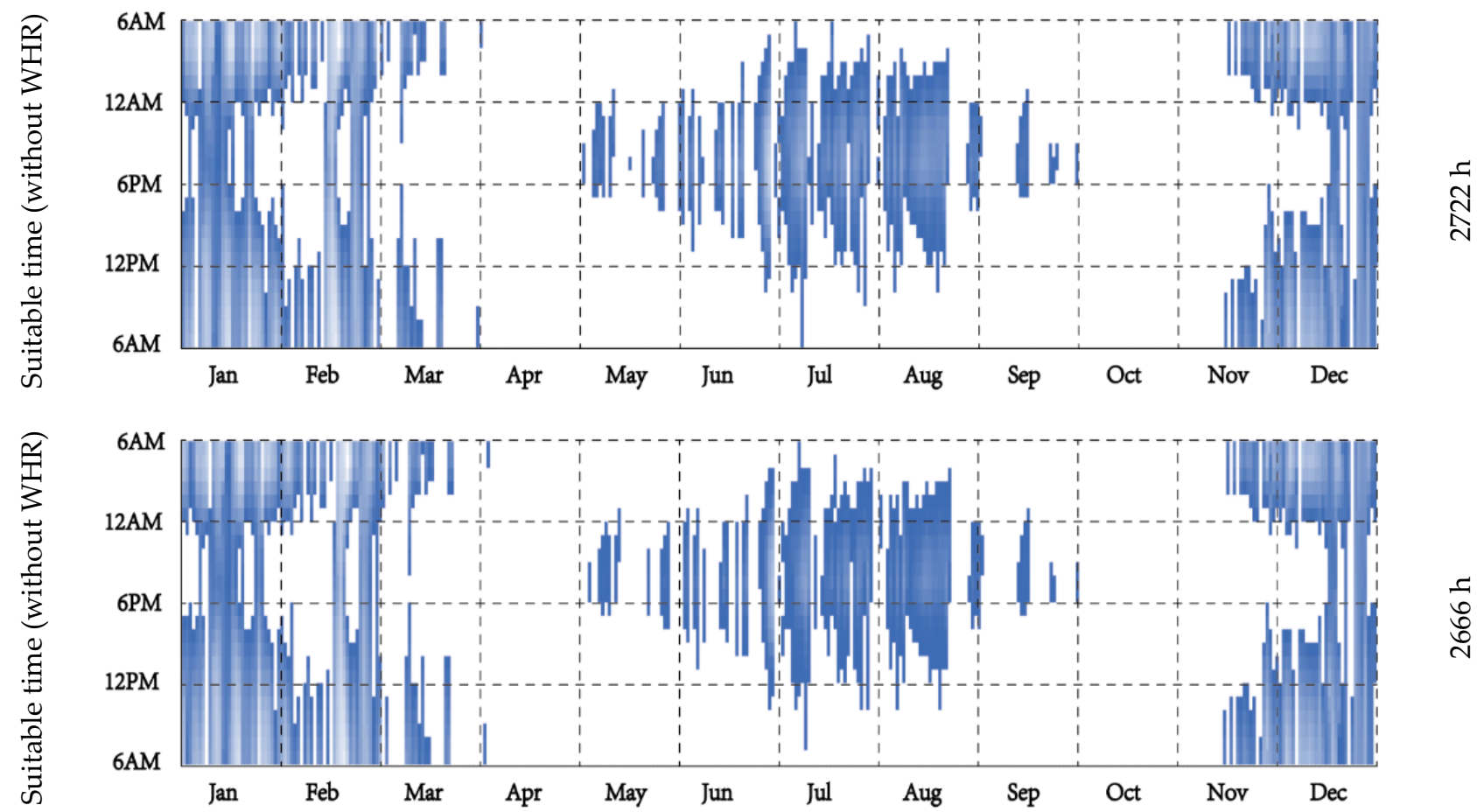

Figure 20. Suitable time for the new system throughout the year.

3.9. Time Suitable for the Building to Meet the Thermal Comfort Temperature after Using the New System

The thermal comfort temperature range obtained after the comfort analysis for Shuhe is shown in Figure 21. It can be seen that under the comprehensive influence, the com- 
fortable temperature range for Shuhe is between $18{ }^{\circ} \mathrm{C}$ and $-25{ }^{\circ} \mathrm{C}$. In this study, the time for the room to meet the thermal comfort zone was counted for the base case, for the case without WHR, and for that with WHR. As shown in Figure 22, the time for the base case to meet the thermal comfort temperature range in a year was $2349 \mathrm{~h}$, accounting for $26.81 \%$ of the year (Figure 22a). After setting up the new system without WHR, the time to meet the thermal comfort temperature range was $2455 \mathrm{~h}$, i.e., an increase of $106 \mathrm{~h}$ and accounting for $28.02 \%$ of the year; thus, the proportion increased by $1.21 \%$ (Figure $22 \mathrm{~b}$ ). With WHR, the time to meet the thermal comfort temperature range was $2420 \mathrm{~h}$, i.e., an increase of $71 \mathrm{~h}$ and accounting for $27.62 \%$ of the year, an increase of $0.81 \%$ (Figure $22 \mathrm{c}$ ). In addition, the time that each room in the building was within the thermal comfort range was calculated separately, as shown in Figure 22d. It can be seen that the comfortable temperature time differed according to the different locations of the rooms. The comfort time of rooms 1-8 with WHR increased significantly, but without WHR, the time was approximately the same as that of the base case. For rooms 9-16, the result was the opposite. However, as compared with the base case, after adding the new system, the time within the comfort range of each room increased, regardless of whether the WHR was considered.
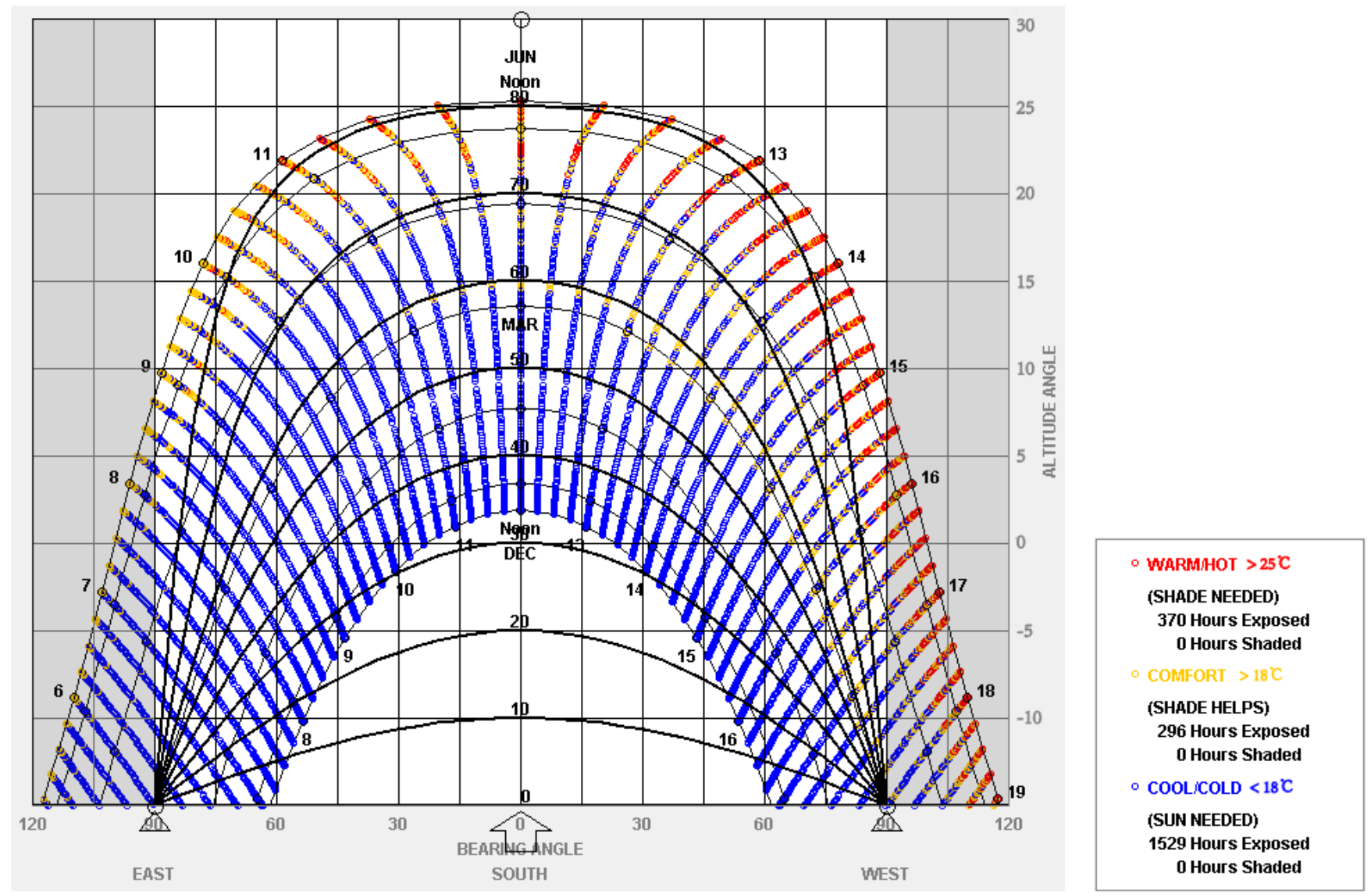

Figure 21. Shuhe thermal comfort temperature range. 


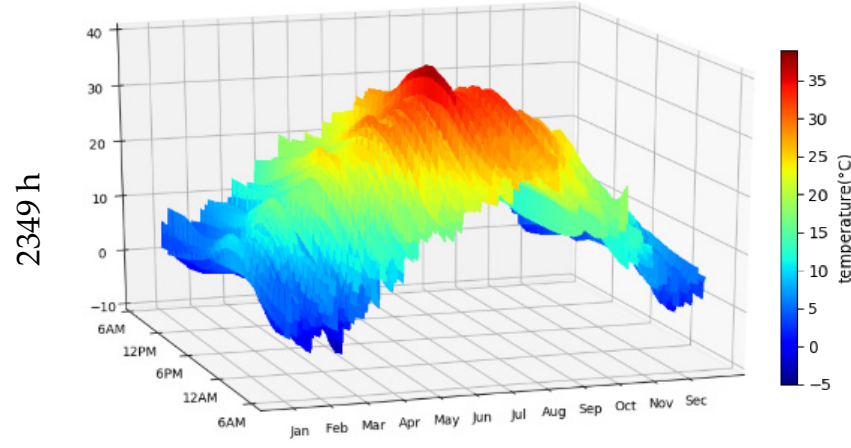

(a) Thermal comfort time of the base case.

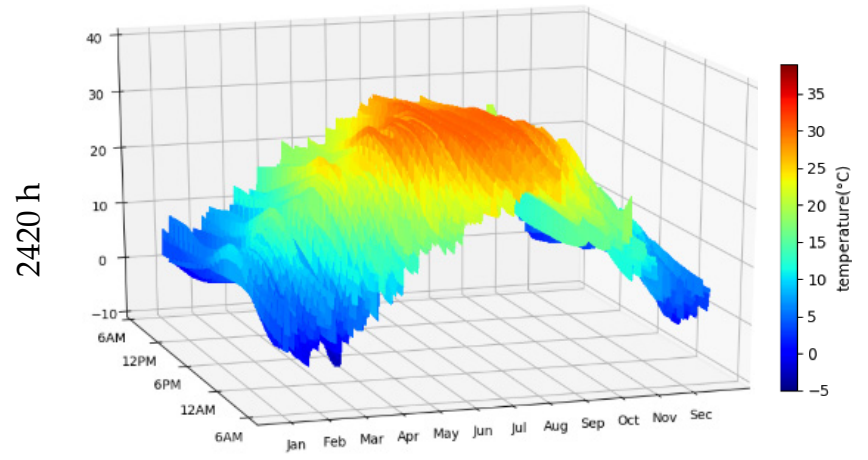

(c) Thermal comfort time of the new system (with WHR).

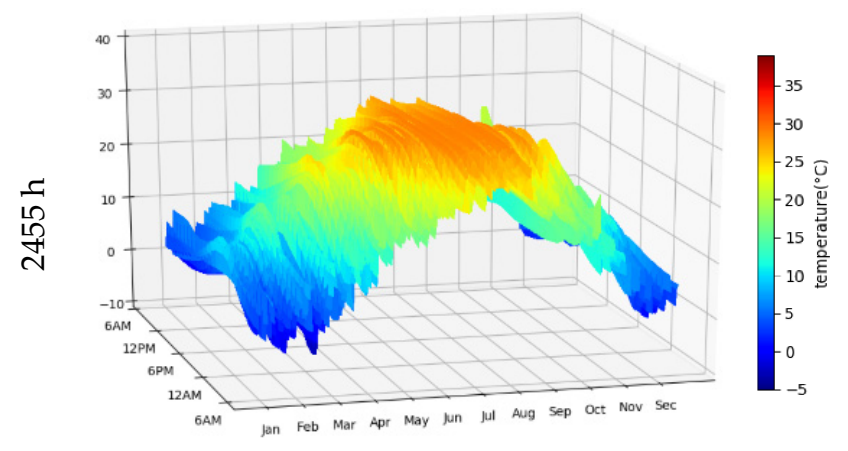

(b) Thermal comfort time of the new system (without WHR).

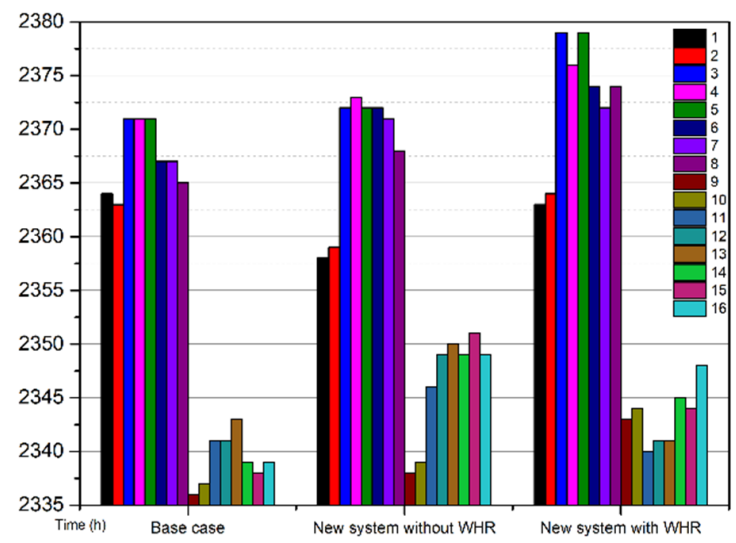

(d) Thermal comfort time of each room of the new system.

Figure 22. Thermal comfort time comparison.

\section{Conclusions and Prospects}

\subsection{Conclusions}

The purpose of this research was to investigate the cooling and ventilation of traditional houses in summer and their heating in winter. In summer, the cold alleys in settlements are used in natural conditions. The cold air in the cold alley is introduced into the room for ventilation and cooling based on hot pressure ventilation the accumulation effect from the courtyard. Air ducts are used to connect the rooms on both sides of the courtyard, greatly improving the cooling efficiency. The cold air trapped in the new system can form an air partition wall, effectively blocking the direct influence of solar radiation on the room, reducing the heat transfer rate of the building wall and consuming part of the heat. After using the new system, the ventilation efficiency of the entire building was greatly improved; this made the air flow in the building more active and facilitated ventilation. In winter, when the air ducts are used as supporting members, a glass roof can be added to the patio. This improved the heat storage capacity of the patio and turned it into a constant-temperature heater for heating the building interior. The cooling load of the air insulation wall, the cooling load and cooling efficiency of the ventilation and cooling from the cold alley, the heating load and heating efficiency of the courtyard heat storage in winter, and the overall cooling and heating efficiencies were calculated. Detailed statistics were calculated regarding the available time for the new system throughout the year, along with the increase in the thermal comfort time of the building in each room after using the new system. The specific conclusions are as follows:

- After the building used the new system, the total cooling load, as reduced by the air insulation wall throughout the year, was $1133.7 \mathrm{kWh}$. After cooling through the cold alley without WHR, the cooling efficiency of the new system was $3.61^{\circ} \mathrm{C} / \mathrm{h}$, and the total cooling load in the building in one year was reduced by $55,417.33 \mathrm{kWh}$. With 
WHR, the cooling efficiency of the new system was $1.03^{\circ} \mathrm{C} / \mathrm{h}$, and the total cooling load was reduced by $28,537.57 \mathrm{kWh}$. This shows that the WHR has a negligible effect on the indoor temperature.

- Adding a glass roof above the patio can increase its heat storage capacity. The patio completed heat storage after $33.3 \mathrm{~min}$, and then began heating the indoor areas. After using the glass roof for a year, the total heating load of the courtyard for the building was $54,537.78 \mathrm{kWh}$.

- After the building used the new system without WHR, the time it took for the room to reach the thermal equilibrium temperature was $1.66 \mathrm{~h}$, and the thermal equilibrium temperature was $28^{\circ} \mathrm{C}$. With WHR, the time for the room to reach the thermal equilibrium temperature was $1.94 \mathrm{~h}$, and the temperature was $32{ }^{\circ} \mathrm{C}$. The ventilation time was shortened from the original $2.22 \mathrm{~h}$ to $4 \mathrm{~min}$; this also shows that the indoor heat transfer rate of the room has nothing to do with the ventilation rate.

- The temperature range for thermal comfort in Shuhe is $18-25^{\circ} \mathrm{C}$. The total time in the base case meeting the thermal comfort temperature over a year was $2349 \mathrm{~h}$, accounting for $26.81 \%$ of the total time of the year. After using the new system without WHR, the annual time meeting the thermal comfort temperature was $2455 \mathrm{~h}$, accounting for $28.02 \%$ of the annual time, and an increase of $106 \mathrm{~h}$ relative to the base case. With WHR, the annual time meeting the thermal comfort temperature in a year was $2420 \mathrm{~h}$, accounting for $27.62 \%$ of the year, an increase of $71 \mathrm{~h}$ relative to the base case. The location of the room affects the temperature in the room, and the thermal comfort time of all rooms decreases after considering the WHR.

\subsection{Prospects}

There are still many important issues that need to be further explored in future research, including the following aspects:

- This study was mainly aimed at completely passive cooling. Owing to the limitations of the air temperature in the cold alley, the room temperature did not reach a comfortable range. In the future, it will be necessary to combine passive cooling with air conditioning to make the room reach a comfortable temperature and calculate the energy consumption of the air conditioning so as to save the energy used by air conditioning to the greatest extent.

- This study mainly used a patio with a heat storage function as a constant temperature heat source but did not describe its specific impact on the room, such as the specific value of the temperature increase in the room. In winter, the factors affecting indoor temperature are not limited to those of the patio; thus, a comprehensive analysis of other factors should be conducted.

- The humidity of the air in the cold alley is relatively high and will have a greater impact on indoor humidity after being introduced into the room. In future research, it will be necessary to consider air humidity as an important reference factor for measuring comfort.

Author Contributions: Conceptualization, X.Y.; methodology, X.Y. and B.J.D.; software, X.Y. and S.H.; investigation, X.Y. and S.H.; writing-original draft preparation, X.Y.; writing-review and editing, X.Y. All authors have read and agreed to the published version of the manuscript.

Funding: This research received no external funding.

Institutional Review Board Statement: Not applicable.

Informed Consent Statement: Not applicable.

Data Availability Statement: Not applicable.

Acknowledgments: The authors thank the professors and students at the University of Kitakyushu for their generous help with the full paper from investigation to the checking process.

Conflicts of Interest: The authors declare no conflict of interest. 


\section{References}

1. Agencia Internacional de la Energía. World Energy Outlook 2017; International Energy Agency together Security Sustainability 2017; OECD: London, UK, 2017.

2. U.S. EIA. Annual Energy Outlook 2018; DOE: Washington, DC, USA, 2018.

3. IEA Online Data Services. Available online: https://www.iea.org/subscribe-to-data-services/world-energybalances-andstatistics (accessed on 15 July 2020).

4. IEA. World Energy Balances 2019 Database Documentation (2019); IEA: Paris, France, 2019.

5. Liu, C.; Xu, W.; Li, A.; Sun, D.; Huo, H. Energy balance evaluation and optimization of photovoltaic systems for zero energy residential buildings in different climate zones of China. J. Clean. Prod. 2019, 235, 1202-1215. [CrossRef]

6. Liu, Z.; Liu, Y.; He, B.-J.; Xu, W.; Jin, G.; Zhang, X. Application and suitability analysis of the key technologies in nearly zero energy buildings in China. Renew. Sustain. Energy Rev. 2019, 101, 329-345. [CrossRef]

7. Hu, W.; Fan, Y. International Energy Agency Transition to Sustainable Buildings: Strategies and Opportunities to 2050; OECD/IEA: Paris, France, 2013.

8. Hu, W.; Fan, Y. City Size and Energy Conservation: Do Large Cities in China Consume More Energy? Energy Econ. 2020, 92, 104943. [CrossRef]

9. World Bank Staff Estimates Based on the United Nations Population Division's World Urbanization Prospects: 2018 Revision; The World Bank, United Nations: New York, NY, USA, 2018.

10. Tahsildoost, M.; Zomorodian, Z. Energy, carbon, and cost analysis of rural housing retrofit in different climates. J. Build. Eng. 2020, 30, 101277. [CrossRef]

11. Yawale, S.K.; Hanaoka, T.; Kapshe, M. Development of energy balance table for rural and urban households and evaluation of energy consumption in Indian states. Renew. Sustain. Energy Rev. 2021, 136, 110392. [CrossRef]

12. Twumasi, M.A.; Jiang, Y.; Ameyaw, B.; Danquah, F.O.; Acheampong, M.O. The impact of credit accessibility on rural households clean cooking energy consumption: The case of Ghana. Energy Rep. 2020, 6, 974-983. [CrossRef]

13. Jiang, L.; Xue, B.; Xing, R.; Chen, X.; Song, L.; Wang, Y.; Coffman, D.; Mi, Z. Rural household energy consumption of farmers and herders in the Qinghai-Tibet Plateau. Energy 2020, 192, 116649. [CrossRef]

14. Wu, S.; Zheng, X.; You, C.; Wei, C. Household energy consumption in rural China: Historical development, present pattern and policy implication. J. Clean. Prod. 2019, 211, 981-991. [CrossRef]

15. Temudo, M.P.; Cabral, A.I.; Talhinhas, P. Urban and rural household energy consumption and deforestation patterns in Zaire province, Northern Angola: A landscape approach. Appl. Geogr. 2020, 119, 102207. [CrossRef]

16. Hao, Y.; Zhu, L.; Ye, M. The dynamic relationship between energy consumption, investment and economic growth in China's rural area: New evidence based on provincial panel data. Energy 2018, 154, 374-382. [CrossRef]

17. Niu, S.; Li, Z.; Qiu, X.; Dai, R.; Wang, X.; Qiang, W.; Hong, Z. Measurement of effective energy consumption in China's rural household sector and policy implication. Energy Policy 2019, 128, 553-564. [CrossRef]

18. Qiu, H.; Yan, J.; Lei, Z.; Sun, D. Rising wages and energy consumption transition in rural China. Energy Policy 2018, 119, 545-553. [CrossRef]

19. Pozas, B.M.; Gamero, I.A.; Domínguez, A.S.; De Castro, P.B.G. A methodology to improve energy efficiency and comfort conditions with low-cost ICTs in rural public buildings. Sustain. Cities Soc. 2020, 60, 102156. [CrossRef]

20. He, B.J.; Yang, L.; Ye, M. Building energy efficiency in China rural areas: Situation, drawbacks, challenges, corre-sponding measures and policies. Sustain. Cities Soc. 2014, 11, 7-15. [CrossRef]

21. Chakraborti, S.; Mondol, J.D.; Smyth, M.; Zacharopoulos, A.; Pugsley, A. Energy consumption levels and technical approaches for supporting development of alternative energy technologies for rural sectors of developing countries. Renew. Sustain. Energy Rev. 2018, 97, 90-102.

22. Wang, W.; Yuan, M.; Li, Y.-Z.; Li, C. Numerical investigation on the impact of an on-top sunspace passive heating approach for typical rural buildings in northern China. Sol. Energy 2019, 186, 300-310. [CrossRef]

23. Boccalatte, A.; Fossa, M.; Gaillard, L.; Menezo, C. Microclimate and urban morphology effects on building energy demand in different European cities. Energy Build. 2020, 224, 110129. [CrossRef]

24. Li, M.; Jin, T.; Liu, S.; Zhou, S. The cost of clean energy transition in rural China: Evidence based on marginal treatment effects Energy Econ. 2021, 97, 105167. [CrossRef]

25. Liu, Y.W.; Feng, W. Integrating passive cooling and solar techniques into the existing building in South China. In Proceedings of the 4th International Conference on Technology of Architecture and Structure (ICTAS 2011), Xi'an, China, 22-24 September 2011; pp. 368-373.

26. Rosti, B.; Omidvar, A.; Monghasemi, N. Optimum position and distribution of insulation layers for exterior walls of a building conditioned by earth-air heat exchanger. Appl. Therm. Eng. 2019, 163, 114362. [CrossRef]

27. Chi, F.; Xu, L.; Peng, C. Integration of completely passive cooling and heating systems with daylighting function into courtyard building towards energy saving. Appl. Energy 2020, 266, 114865. [CrossRef]

28. Fiaschi, D.; Bertolli, A. Design and energy analysis of solar roofs: A viable solution with esthetic appeal to collect solar heat. Renew Energy 2012, 46, 60-71. [CrossRef]

29. Kishore, R.A.; Bianchi, M.V.; Booten, C.; Vidal, J.; Jackson, R. Enhancing building energy performance by effectively using phase change material and dynamic insulation in walls. Appl. Energy 2021, 283, 116306. [CrossRef] 
30. Zhang, L.; Liu, Z.; Hou, C.; Hou, J.; Wei, D.; Hou, Y. Optimization analysis of thermal insulation layer attributes of building envelope exterior wall based on DeST and life cycle economic evaluation. Case Stud. Therm. Eng. 2019, 14, 100410. [CrossRef]

31. Wang, J.; Du, Q.; Zhang, C.; Xu, X.; Gang, W. Mechanism and preliminary performance analysis of exhaust air insulation for building envelope wall. Energy Build. 2018, 173, 516-529. [CrossRef]

32. Mahlia, T.M.I.; Iqbal, A. Cost benefits analysis and emission reductions of optimum thickness and air gaps for selected in-sulation materials for building walls in Maldives. Energy 2010, 35, 2242-2250. [CrossRef]

33. Chandel, S.; Sarkar, A. Performance assessment of a passive solar building for thermal comfort and energy saving in a hilly terrain of India. Energy Build. 2015, 86, 873-885. [CrossRef]

34. Bhamare, D.K.; Rathod, M.K.; Banerjee, J. Passive cooling techniques for building and their applica-bility in different climatic zones-The state of art. Energy Build. 2019, 198, 467-490. [CrossRef]

35. Serageldin, A.A.; Abdeen, A.; Ahmed, M.M.; Radwan, A.; Shmroukh, A.N.; Ookawara, S. Solar chimney combined with earth to-air heat exchanger for passive cooling of residential buildings in hot areas. Sol. Energy 2020, 206, 145-162. [CrossRef]

36. Vaseghi, M.; Fazel, M.; Ekhlassi, A. Numerical investigation of solar radiation effect on passive and active heating and cooling system of a concept museum building. Therm. Sci. Eng. Prog. 2020, 19, 100582. [CrossRef]

37. Sivaram, P.; Mande, A.B.; Premalatha, M.; Arunagiri, A. Investigation on a building-integrated passive solar energy technology for air ventilation, clean water and power. Energy Convers. Manag. 2020, 211, 112739. [CrossRef]

38. Layeni, A.T.; Waheed, M.A.; Adewumi, B.A.; Bolaji, B.O.; Nwaokocha, C.N.; Giwa, S.O. Computational modelling and simulation of the feasibility of a novel dual purpose solar chimney for power generation and passive ventilation in buildings. Sci. Afr. 2020, 8, e00298. [CrossRef]

39. Zhang, R.; Nie, Y.; Lam, K.P.; Biegler, L.T. Dynamic optimization based integrated operation strategy design for passive cooling ventilation and active building air conditioning. Energy Build. 2014, 85, 126-135. [CrossRef]

40. Yeh, S.-C.; Whang, A.J.-W.; Hsiao, H.-C.; Hu, X.-D.; Chen, Y.-Y. Distribution of Emerged Energy for Daylight Illuminate on Prismatic Elements. J. Sol. Energy Eng. 2011, 133, 021007. [CrossRef]

41. Mao, Q.; Yang, M. Experimental and numerical investigation on heat transfer performance of a solar double-slope hollow glazed roof. Appl. Therm. Eng. 2020, 180, 115832. [CrossRef]

42. Yi, Z.; Lv, Y.; Xu, D.; Xu, J.; Qian, H.; Zhao, D.; Yang, R. Energy saving analysis of a transparent radiative cooling film for buildings with roof glazing. Energy Built Environ. 2021, 2, 214-222. [CrossRef]

43. Li, D.; Wu, Y.; Zhang, G.; Arıc1, M.; Liu, C.; Wang, F. Influence of glazed roof containing phase change material on indoor thermal environment and energy consumption. Appl. Energy 2018, 222, 343-350. [CrossRef]

44. Pourrahmani, H.; Moghimi, M. Exergoeconomic analysis and multi-objective optimization of a novel continuous solar-driven hydrogen production system assisted by phase change material thermal storage system. Energy 2019, 189, 116170. [CrossRef]

45. Muselli, M. Passive cooling for air-conditioning energy savings with new radiative low-cost coatings. Energy Build. 2010, 42, 945-954. [CrossRef]

46. Zheng, C.; Wu, P.; Costanzo, V.; Wang, Y.; Yang, X. Establishment and Verification of Solar Radiation Calculation Model of Glass Daylighting Roof in Hot Summer and Warm Winter Zone in China. Procedia Eng. 2017, 205, 2903-2909. [CrossRef]

47. Bruno, R.; Bevilacqua, P.; Arcuri, N. Green roofs as passive system to moderate building cooling requirements and UHI effects: Assessments by means of experimental data. In Woodhead Publishing Series in Civil and Structural Engineering, Eco-efficient Materials for Reducing Cooling Needs in Buildings and Construction; Pacheco-Torgal, F., Czarnecki, L., Laura Pisello, A., Cabeza, L.F., Granqvist, C.-G., Eds.; Woodhead Publishing: Sawston, UK, 2021; pp. 205-245. [CrossRef]

48. Prieto, A.; Knaack, U.; Auer, T.; Klein, T. Passive cooling \& climate responsive façade design: Ex-ploring the limits of passive cooling strategies to improve the performance of commercial buildings in warm climates. Energy Build. 2018, 175, 30-47.

49. Yao, X.; Dewancker, B.; Guo, Y.; Han, S.; Xu, J. Study on Passive Ventilation and Cooling Strategies for Cold Lanes and Courtyard Houses-A Case Study of Rural Traditional Village in Shaanxi, China. Sustainability 2020, 12, 8687. [CrossRef]

50. Staveckis, A.; Borodinecs, A. Impact of impinging jet ventilation on thermal comfort and indoor air quality in office buildings. Energy Build. 2021, 235, 110738. [CrossRef]

51. Zhang, X.; Weerasuriya, A.U.; Tse, K.T. CFD simulation of natural ventilation of a generic building in various incident wind directions: Comparison of turbulence modelling, evaluation methods, and ventilation mechanisms. Energy Build. 2020, $229,110516$. [CrossRef]

52. Blocken, B. LES over RANS in building simulation for outdoor and indoor applications: A foregone conclusion? Build. Simul. 2018, 11, 821-870. [CrossRef]

53. Zhang, M.; Li, R.; Wu, Y.; Wang, L.; Song, G.; Li, J. Numerical study of the convective heat transfer coefficient of the hand and the effect of wind. Build. Environ. 2021, 188, 107482. [CrossRef]

54. Yang, J.-H.; Kato, S.; Seo, J. Evaluation of the Convective Heat Transfer Coefficient of the Human Body Using the Wind Tunnel and Thermal Manikin. J. Asian Arch. Build. Eng. 2009, 8, 563-569. [CrossRef]

55. Gao, S.; Ooka, R.; Oh, W. Formulation of human body heat transfer coefficient under various ambient temperature, air speed and direction based on experiments and CFD. Build. Environ. 2019, 160, 106168. [CrossRef]

56. Zhang, R.; Lam, K.P.; Yao, S.C.; Zhang, Y. Coupled EnergyPlus and computational fluid dynamics simu-lation for natural ventilation. Build. Environ. 2013, 68, 100-113. [CrossRef] 